\author{
UNIVERSIDADE DE SÃO PAULO \\ FACULDADE DE MEDICINA DE RIBEIRÃO PRETO
}

TOMÁS ROTELLI DE OLIVEIRA FERREIRA

\title{
Avaliação da sala de aula invertida para capacitação em saúde mental de equipes da estratégia de saúde da família
}


TOMÁS ROTELLI DE OLIVEIRA FERREIRA

\section{Avaliação da sala de aula invertida para capacitação em saúde mental de equipes da estratégia de saúde da família.}

"Versão corrigida. A versão original encontra-se disponível tanto na Biblioteca da Unidade que aloja o Programa, quanto na Biblioteca Digital de Teses e Dissertações da USP (BDTD)"

Dissertação apresentada à Faculdade de Medicina de Ribeirão Preto da Universidade de São Paulo, para obtenção do título de Mestre em Educação em Saúde, Programa de Pós Graduação em Clínica Médica.

Área de concentração: Clínica Médica

Orientador: Prof. Dr. Valdes Roberto Bollela

Ribeirão Preto 
Autorizo a reprodução e divulgação total ou parcial deste trabalho, por qualquer meio de convencional ou eletrônico, para fins de estudo e pesquisa, desde que citada a fonte.

FERREIRA, Tomás Rotelli de Oliveira

Avaliação da sala de aula invertida para capacitação em saúde mental de equipes de estratégia de saúde da família. 69p.

Dissertação (Mestrado de Educação em Saúde), apresentada à Faculdade de Medicina de Ribeirão Preto/USP. Área de concentração: Educação em Saúde

Orientador: Prof. Dr. Valdes Roberto Bollela

\section{Versão Original}

1 Educação Permanente. 2 Educação a distância. 3 Saúde Mental. 4 Atenção primária à saúde. 
Nome: FERREIRA, Tomás Rotelli de Oliveira

Título: Avaliação da sala de aula invertida para capacitação em saúde mental de equipes da estratégia de saúde da família.

Dissertação apresentada à Faculdade de Medicina de Ribeirão Preto da Universidade de São Paulo, para obtenção do título de Mestre em Educação em Saúde, Programa de Pós Graduação em Clínica Médica.

Aprovada em

Banca Examinadora

Prof.(a) Dr.(a)

Instituição:

Julgamento:

Prof.(a) Dr.(a)

Instituição:

Julgamento:

Prof.(a) Dr.(a)

Instituição:

Julgamento: 


\section{DEDICATÓRIA}

A todos profissionais de saúde que se

permitem serem tocados pelo sofrimento alheio. 


\section{AGRADECIMENTOS}

Agradeço ao meu orientador, amigo e mentor Prof. Dr. Valdes Roberto Bollela, que sempre me incentivou, motivou e guiou no caminho do ensinar. Obrigado por todo encorajamento e disponibilidade para me ajudar ao longo dos últimos anos!

Agradeço a Luiza, grande amor da minha vida, que sempre acreditou eu mim, me apoiou, me incentiva a crescer e a me tornar uma pessoa melhor. Não chegaria a onde estou sem você. Sempre juntos!

Agradeço aos meus pais, José e Márcia, por me apresentarem ao caminho do estudo, da dedicação, honestidade e trabalho duro. Obrigado por todo carinho e amor!

Agradeço aos meus irmãos, Elisa e Lucas, pela amizade, amor e companheirismo que sempre tiveram!

Agradeço a minha amiga e terapeuta Telma, que me ajudou a clarear quais caminhos trilhar ao longo dos últimos anos.

Agradeço aos professores e preceptores do Departamento de Neurociências da FMRP-USP, em especial a Dra. Arlete, Dr. Vinícius e Dr. Alan, cuja paixão pelo ensino me instigou a seguir a vida acadêmica.

Agradeço a todos membros Secretaria de Saúde de Uberaba e a todos os funcionários das equipes de saúde da família que colaboraram com a execução deste trabalho.

Agradeço ao meu amigo Dr. Mário por acreditar e me ajudar a acreditar em meu próprio potencial como profissional da educação.

Por fim, agradeço a Faculdade de Medicina de Ribeirão Preto - USP por proporcionar meu crescimento pessoal e profissional. 


\section{RESUMO}

\section{TOMAS, TRO. Avaliação da sala de aula invertida para capacitação em saúde mental de} equipes da estratégia de saúde da família. 2019. 69p. Dissertação (Mestrado em Educação em Saúde) - Faculdade de Medicina de Ribeirão Preto, Universidade de São Paulo, Ribeirão Preto, 2019.

Pesquisas apontam que grande parte dos profissionais da atenção básica se sente despreparada para lidar com as demandas em saúde mental, o que poderia ser explicado pela falta de oportunidades de capacitação nesse tema. Este estudo teve como objetivo comparar e analisar o uso de duas estratégias de ensino diferentes (sala de aula invertida e ensino presencial) para capacitação em saúde mental de equipes da estratégia de saúde da família. Estudo realizado na cidade de Uberaba, interior do estado de Minas Gerais, com 134 profissionais (incluindo aqueles com ensino superior, técnico e agentes comunitários de saúde). Os profissionais foram divididos em dois grupos, um com 70 pessoas que recebeu capacitação utilizando ensino exclusivamente presencial e outro com 64 profissionais utilizando sala de aula de aula invertida, que previa cerca de cinco horas e meia de atividades caracterizadas como ensino a distância. Ambas turmas reportaram elevados níveis de satisfação com o curso, tiveram auto percepção de aprendizagem semelhante (pré- e pós-intervenção), o que foi evidenciado também pela avaliação cognitiva feita através de uma prova discursiva sobre os temas do curso. $\mathrm{O}$ maior desafio da sala de aula invertida foi a adesão à utilização do material de ensino a distância, mas a estratégia foi capaz de proporcionar aprendizado semelhante em tempo inferior e com maior flexibilidade para os estudantes, se comparada a proposta da educação presencial.

Descritores: Educação Permanente. Educação a distância. Saúde Mental. Atenção primária à saúde. 


\begin{abstract}
TOMAS, TRO. Evaluating flipped classroom training in mental health to the family health strategy team. 2019. Dissertation. 69p. Ribeirão Preto`s Medicine College, São Paulo University, Ribeirão Preto, 2019.

Researches show that most of primary care professionals feel unprepared to deal with the demands on mental health, which might be explained by the lack of training opportunities for the demands of this theme. This study aimed to compare and analyze the use of two different teaching strategies (flipped classroom and face-to-face teaching) for personnel's training on mental health for the family health strategy. The study was conducted in the city of Uberaba, in the countryside of the state of Minas Gerais, with 134 professionals (including higher education, certificate programs and community health agents). The professionals were divided in two groups, one with 70 individuals that received exclusively face-to-face teaching training, and another with 64 professionals through flipped classroom, a course with five hours and thirty minutes of distance education activities. Booth groups reported high levels of satisfaction regarding the course, they had similar self-perceived learning (pre- and postintervention), which was also highlighted by the cognitive evaluation that was made through a discursive test on the subjects of the course. The largest challenge of the flipped classroom was the accession to the use of the distance education material; however, the strategy was able to provide similar learning in a shorter duration and with greater flexibility for the students if compared to the distance education purpose.
\end{abstract}

Keywords: Permanent Education. Distance Education. Mental Health. Primary Care. 


\title{
LISTA DE SIGLAS
}

\author{
SAI Sala de Aula Invertida \\ EP Ensino Presencial \\ ESF Estratégia de Saúde da Família \\ ACS Agente Comunitário de Saúde \\ USP Universidade de São Paulo \\ TM Transtornos Mentais \\ AB Atenção Básica
}




\section{SUMÁRIO}

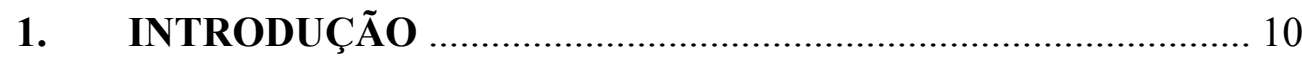

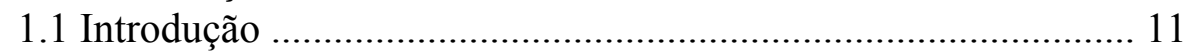

1.2 Revisão da Literatura .............................................................. 12

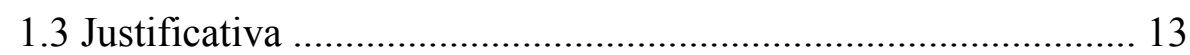

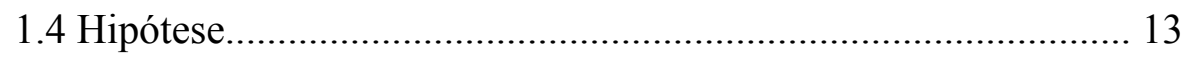

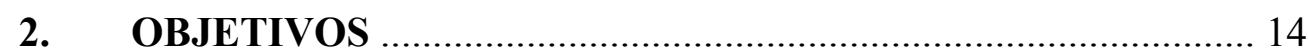

2.1 Objetivo geral …………………………………………..... 15

2.2 Objetivos específicos …………………………………………. 15

3. MATERIAL E MÉTODOS …………………………………….... 16

3.1 Referencial teórico e tipo de estudo ............................................ 17

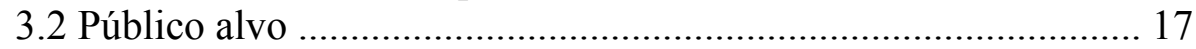

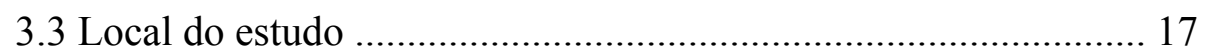

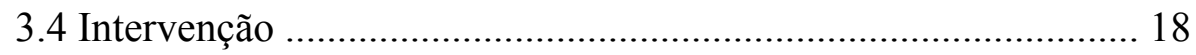

3.5 Instrumentos de coleta de dados ................................................ 22

3.6 Análise dos resultados quantitativos ............................................ 23

3.7 Análise dos resultados qualitativos ............................................. 24

3.8 Aspectos éticos …………………………………………….... 25

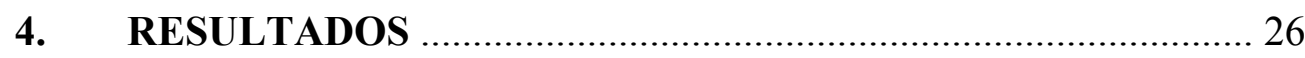

4.1 Caracterização dos participantes ……………………………..... 27

4.1.1 Número de participantes e distribuição das categorias

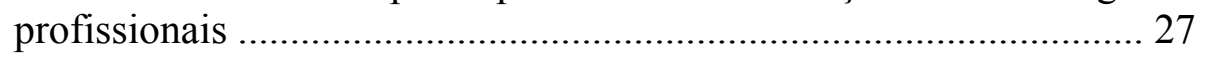

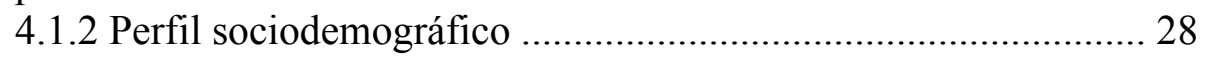

4.1.3 Caracterização do acesso e uso da internet .............................. 29

4.2 Carga horária dos cursos .............................................................29

4.3 Avaliação de desempenho de cada grupo após prova escrita........30

4.4 Auto avaliação de aprendizagem................................................... 32

4.5 Feedback sobre o curso.............................................................. 35

4.6 Assiduidade no uso do material de ensino a distância .................. 42

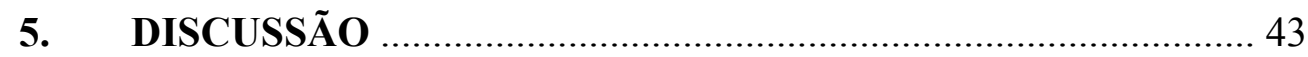

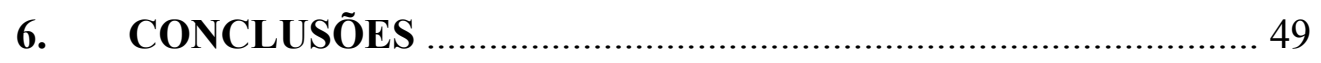

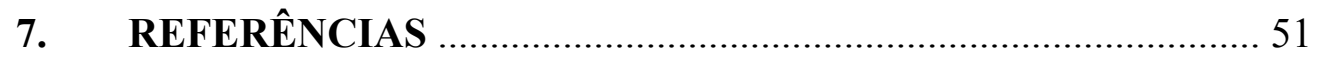

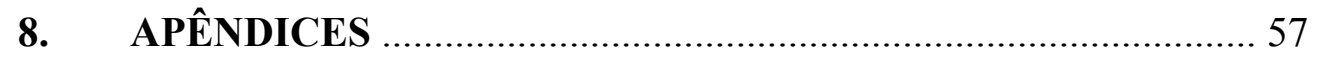




\subsection{Introdução}

Estudos nacionais (VALENTINI 2004; VECCHIA 2009; CAVALCANTE 2010; GRYSCHEK 2015) e internacionais (KAKUMA 2011; MEDINA 2014; ATHIE 2016) apontam que grande parte dos profissionais atuantes na atenção básica $(A B)$ se sente despreparada para lidar com as demandas em saúde mental e que há uma baixa capacidade diagnóstica dos transtornos mentais (TM) por parte dos clínicos gerais.

Mitchell (2009), em uma metanálise feita a partir de 41 estudos com mais de cinquenta mil pacientes, observou que somente $47,3 \%$ dos casos de depressão foram reconhecidos por clínicos gerais atuantes na AB. Um outro estudo realizado por Carey (2014) apresenta valores muito parecidos, com uma detecção de apenas $51 \%$ dos casos de depressão pelos profissionais que atuam na $\mathrm{AB}$ da Austrália.

Uma revisão da literatura realizada por Correia et al. (2011) aponta que as ações em saúde mental são arbitrariamente escolhidas de acordo com o profissional e gestor local, e conclui que "a melhor estratégia para conseguir êxito na assistência ao doente mental no PSF foi o investimento na qualificação dos profissionais através de educação e capacitação permanente nesta área".

Profissionais de saúde preparados para oferecer cuidado de qualidade em saúde mental são prioridade na $\mathrm{AB}$, especialmente após a criação da Rede de Atenção Psicossocial (RAPS) pela portaria $\mathrm{N}^{\mathrm{o}} 3.088$ de 23 de dezembro de 2011. Tal portaria inclui este nível de atenção como principal ponto de apoio e tratamento para pessoas com sofrimento psíquico e/ou transtornos mentais.

Os estudos a respeito da efetividade da capacitação em saúde mental para equipes de $\mathrm{AB}$ mostram resultados controversos. Alguns estudos mostram benefícios limitados ou ausentes sob o aspecto de aumento do número de pacientes diagnosticados com depressão e melhora clínica desses pacientes (LIN 1997; THOMPSON 2000; ELIZABETH 2001; VALENTINI 2004; LEVAV 2005); GONÇALVES 2013). Entretanto outras pesquisas mostram resultados positivos como melhora na capacidade de diagnóstico, na atitude em relação aos TM e melhoria no prognóstico dos pacientes (TIEMENS 1999; KUTCHER 2002; KUTCHER 2003; TITUS 2004; TURRINA 2008; NORTON 2011). Uma revisão sistemática concluiu que a maioria das intervenções (sete de nove) de capacitação em saúde mental trouxe resultados positivos (VOHRINGER 2016).

Contudo, o que praticamente não é abordado nesses estudos diz respeito a quais estratégias de ensino e aprendizagem poderiam influenciar negativa ou positivamente na 
qualificação dos profissionais em temas relacionados a saúde mental. Como o foco dos estudos é voltado para resultados ligados a mudanças nas habilidades, atitudes e conhecimentos após intervenção com formato único, não temos muitas informações sobre qual seria a influência do método de ensino empregado nestes treinamentos.

\subsection{Revisão da Literatura}

A política nacional de saúde mental prioriza a implementação de uma rede diversificada de serviços em saúde mental, colocando a $\mathrm{AB}$ como componente fundamental da mesma (BRASIL, 2016), modelo que segue o paradigma proposto pela organização mundial da saúde (OMS, 2014).

Contudo, estudos qualitativos indicam que os profissionais que ali atuam relatam sensação de despreparo e falta de capacidade técnica para lidar com transtornos mentias (OLIVEIRA, 2008, VECCHIA, 2009; CAVALCANTE, 2010; MEDINA, 2014; ATHIE, 2016). Outras pesquisas revelam uma sensibilidade diagnóstica baixa, com detecção de cerca de 50\% dos casos (MITCHEL, 2009; CAREY, 2014; OLARIU, 2015).

Sendo assim, torna-se imprescindível a qualificação dos profissionais da $\mathrm{AB}$ através da capacitação. Essa é uma ferramenta de imensurável importância para o desenvolvimento dos recursos humanos, pois estabelece um elo entre a experiência teórica e a prática profissional, fornecendo uma oportunidade única de reflexão em prol de melhorias constantes (GUIMARÃES; MARTIN; RABELO, 2010). Entretanto, poucos estudos se propõem a avaliar as limitações e potencialidades de diferentes metodologias de ensino, evidenciando uma área de investigação a ser desbravada.

O ensino presencial (EP) pode ser organizado e oferecido utilizando uma grande diversidade de estratégias de ensino como: aula expositiva; aprendizado baseado em problemas, estudo de caso, seminário, dramatização, júri simulado, dentre tantos outros (ANASTASIOU, 2012). O EP não foca tanto na estratégia específica de ensino, mas sim no ambiente de aprendizagem e no fato de aprendizes e professores estarem face a face. Atualmente é preconizado que o EP não se paute exclusivamente em aulas expositivas, pois há várias vantagens na utilização de metodologias de ensino ativas, centradas no estudante e em grupo, como o estímulo do pensamento crítico reflexivo e aquisição de habilidades. (SOUZA, 2014).

Outra possível forma de desenhar um curso e que vem ganhando força nos últimos anos é o da sala de aula invertida (SAI) (do inglês flipped classroom). Esse tipo de abordagem 
didático-pedagógica combina técnicas de educação a distância (EAD) mediados por tecnologia e encontros presenciais. São utilizados como recursos videoaulas, textos e pequenos questionários estruturados a serem utilizados antes do encontro presencial. Assim, o tempo na sala de aula é reservado para atividades mais interativas e metodologias ativas de ensino, como: resolução de problemas, treinamento de habilidades práticas, aplicação de conceitos, discussões em grupo, simulações, dentre outros (MARGULIEUX, 2013; SHARMA, 2015; BOLLELA, 2017).

Uma revisão sistemática recente sobre o uso da SAI na graduação de medicina selecionou 46 artigos, dos quais apenas nove realizaram um comparativo entre grupo intervenção (Sala de Aula Invertida) e grupo controle (Ensino Presencial) (CHEN, 2017). Os autores concluíram que a SAI produziu bons resultados de satisfação com ganho de conhecimento ao menos semelhante ao ensino tradicional, mas sem evidência de superioridade.

Em uma metanálise com 28 estudos concluiu-se que a SAI produz maior aprendizado se comparada a educação tradicional (HEW, 2018). Somente dois entre os vinte e oito estudos dessa metanálise incluíram profissionais de saúde formados, os quais estavam realizando cursos de pós-graduação. Todas as demais pesquisas foram focadas em disciplinas de graduação de cursos de saúde, como medicina, enfermagem e farmácia. Assim, tornam-se necessários estudos que avaliem as potencialidades e limitações da SAI fora do contexto da graduação, como por exemplo na capacitação de profissionais de saúde.

\subsection{Justificativa}

Este trabalho advém da reflexão sobre a $\mathrm{AB}$ ser inserida como principal ponto de apoio na rede de atenção psicossocial sem que os profissionais ali atuantes gozem de qualificação nesta área. Sendo assim, este projeto visa contribuir para suprir a lacuna de conhecimento que interfere nas práticas de cuidado em saúde mental e possibilitar uma análise sobre quais recursos didáticos de ensino atenderiam melhor as ações de capacitação.

\subsection{Hipótese}

A metodologia de sala de aula invertida produz ao menos o mesmo aprendizado e satisfação quando comparada ao ensino presencial na capacitação em saúde mental de profissionais da equipe de saúde da família. 
2- OBJETIVOS 


\subsection{Objetivo Geral}

Avaliar as potencialidades e limitações de duas abordagens metodológicas distintas de capacitação em saúde mental direcionadas para equipes de saúde da família.

\subsection{Objetivos Específicos}

- Caracterizar o perfil sociodemográfico dos profissionais de saúde atuantes em equipes da estratégia de saúde da família de Uberaba;

- Avaliar e comparar duas estratégias distintas de ensino e aprendizagem (ensino presencial versus sala de aula invertida);

- Avaliar o nível de aprendizado entre profissionais da equipe de saúde da família nos dois formatos de capacitação (ensino presencial versus sala de aula invertida);

- Avaliar e descrever a percepção sobre a qualidade metodológica do curso nos dois formatos de capacitação (ensino presencial e sala de aula invertida); 


\subsection{Referencial Teórico e Tipo de Estudo}

Este estudo caracteriza-se como uma pesquisa-ação, modalidade extensamente utilizada em projetos de intervenção educacional que visam "principalmente uma estratégia para o desenvolvimento de professores e pesquisadores de modo que eles possam utilizar suas pesquisas para aprimorar seu ensino e, em decorrência, o aprendizado de seus alunos" (TRIPP, 2005). Segundo Tripp, a "pesquisa-ação é uma forma de investigação-ação que utiliza técnicas de pesquisa consagradas para informar a ação que se decide tomar para melhorar a prática".

Essa modalidade de pesquisa segue quatro fases: planejar uma melhora da prática, agir para implantar a melhora planejada, monitorar e descrever os efeitos da ação e, por fim, avaliar os resultados da ação (TRIPP, 2005).

\subsection{Público-alvo}

A pesquisa teve como público alvo todos os profissionais atuantes em doze equipes de estratégia de saúde da família do munícipio de Uberaba-MG (médicos, enfermeiros, dentistas, técnicos de enfermagem, técnicos de saúde bucal e agentes comunitários de saúde). A escolha dessas equipes se deu por indicação da Secretaria Municipal de Saúde do Município após análise dos serviços em relação a disponibilidade e necessidade local. A diretoria de atenção básica realizou o convite aos participantes por meio digital e por contato verbal realizado através dos gerentes das eESF.

As doze equipes foram divididas em dois grupos de seis equipes, sendo um alocado para o curso com a metodologia de EP e outro para a metodologia de SAI. Os critérios de inclusão utilizados foram: ser membro da equipe de saúde da família; concordar em participar do estudo e assinar o termo de consentimento livre e esclarecido (TCLE).

Já os critérios de exclusão do estudo foram: não comparecer em ao menos $75 \%$ da carga horária do curso e não preencher os questionários da pesquisa.

\subsection{Local do Estudo}

Uberaba, cidade onde foi realizado este estudo, possuía 51 Equipes de Saúde da Família em 2016 (PREFEITURA DO MUNICÍPIO DE UBERABA, 2016), fornecendo uma cobertura mais de metade dos 325.000 habitantes. Ações de capacitação incluindo todos os 
membros da equipe de saúde da família (ESF) são costumeiramente ofertadas pela secretaria de saúde do município. Não haviam sido realizadas ações educativas em saúde mental ou psiquiatria até o final de 2016 fora da temática de dependência química. Portanto havia clara demanda para a realização de ações de capacitação sobre saúde mental a nível local.

Os encontros presenciais puderam ser realizados em sala de aula da própria secretaria de saúde do município, nos períodos da manhã e da tarde das sextas feiras. Assim, os participantes puderam comparecer no curso em horário de trabalho, sem qualquer prejuízo quanto a sua remuneração.

\subsection{Intervenção}

Foi realizado um curso piloto com características semelhantes ao curso de ensino presencial, descrito abaixo. Através deste piloto foi possível melhor selecionar os tópicos de ensino, definir o número necessário de encontros presenciais, estimar a carga horária total e testar a prova de conhecimentos específicos.

Foram elaborados dois formatos de cursos para capacitação em saúde mental: um exclusivamente pautado no ensino presencial (EP) e outro no formato de sala de aula invertida (SAI). Os cursos tiveram duração prevista de aproximadamente 22 horas distribuídos ao longo de oito encontros no EP e seis encontros no formato de SAI. Tal diferença no número de encontros ocorre por conta de parte da carga horaria na SAI ocorrer pelo ensino a distância (EAD).

No EP, o pesquisador utilizou aulas expositivas dialogadas e fez uso de metodologias ativas de ensino: simulações, discussões de caso clínico, discussão sobre entrevistas gravadas com pacientes simulados, aplicação de questionários, treinamento de contenção física e dinâmicas. Vale ressaltar que ambos cursos utilizaram das mesmas atividades de metodologias ativas de ensino, se diferenciando exclusivamente pela substituição de aulas expositivas pela educação a distância.

Para a efetuação da SAI, quase todas aulas expositivas foram substituídas por EAD no formato de videoaulas e textos didáticos com objetivo de trabalhar conceitos teóricos. Tais videoaulas foram confeccionadas pela gravação de apresentação de slides com gravação de voz sobre o vídeo. Cada videoaula teve duração de 10 a 20 minutos e foram disponibilizadas em ambiente virtual de livre acesso (youtube). Já os textos didáticos foram confeccionados antevendo a possibilidade de parte dos participantes não terem acesso à internet ou de preferirem esse recurso ao audiovisual. Assim, o tempo de encontro presencial foi utilizado 
principalmente para utilização de metodologias ativas de ensino com objetivo de consolidar o aprendizado a distância, trabalhar a aplicação de conceitos, promover o aprendizado entre pares e o trabalho em equipe multiprofissional. Foram confeccionadas videoaulas e textos didáticos diferentes para os profissionais de ensino superior (médicos, dentistas e enfermeiros) e para os demais participantes (profissionais de ensino técnico e agentes comunitários de saúde).

Os temas abordados no curso EP e SAI foram os mesmos, utilizando referências atualizadas para o ano do estudo, como Manual Diagnóstico e Estatístico $5^{\mathrm{a}}$ edição, Kaplan and Sadock`s Synopsis of Psychiatry 11th edition e The Maudsley Prescribing Guidelines in Psychiatry 12th edition. Ambas as turmas puderam optar por um tema extra e ambas escolheram o tema de transtornos mentais na infância. Mais detalhes sobre as temáticas abordadas em ambos cursos estão disponíveis nos quadros 1 e 2, a seguir. 
Quadro 1 - Temas abordados e metodologias utilizadas no ensino presencial.

\begin{tabular}{|c|c|c|}
\hline Encontro & Tema Abordado & Metodologias \\
\hline 1 & $\begin{array}{l}\text { Introdução; Família na } \\
\text { perspectiva sistêmica; Rede de } \\
\text { Atenção Psicossocial de } \\
\text { Uberaba; Diagnóstico na } \\
\text { Psiquiatria }\end{array}$ & $\begin{array}{l}\text { Aulas Expositivas; Discussão de caso } \\
\text { clínico; Aplicação de questionário } \\
\text { sóciodemográfico e TCLE. }\end{array}$ \\
\hline 2 & $\begin{array}{l}\text { Antidepressivos e } \\
\text { Benzodiazepínicos. }\end{array}$ & $\begin{array}{l}\text { Aulas Expositivas; Resposta de } \\
\text { questionamentos em grupo; Dinâmica } \\
\text { (crenças sobre psicofármacos) }\end{array}$ \\
\hline 3 & $\begin{array}{l}\text { Transtorno Depressivo e } \\
\text { Suicídio. }\end{array}$ & $\begin{array}{l}\text { Aula expositiva; Estudo de caso; } \\
\text { Discussão de caso clínico }\end{array}$ \\
\hline 4 & Transtornos de Ansiedade & $\begin{array}{l}\text { Aulas expositivas; Discussão de casos } \\
\text { clínicos; Exposição de entrevistas } \\
\text { gravadas com atores simulando } \\
\text { transtornos de ansiedade. }\end{array}$ \\
\hline 5 & $\begin{array}{l}\text { Esquizofrenia; transtorno } \\
\text { bipolar e transtorno borderline. }\end{array}$ & $\begin{array}{l}\text { Aulas Expositivas; Dinâmica } \\
\text { (preconceitos com transtorno mental) }\end{array}$ \\
\hline 6 & $\begin{array}{l}\text { Autismo*; Deficiência } \\
\text { Intelectual*; Transtorno do } \\
\text { déficit de atenção e } \\
\text { hiperatividade*. }\end{array}$ & Aulas Expositivas. \\
\hline 7 & $\begin{array}{l}\text { Demência; insônia e higiene } \\
\text { do sono. }\end{array}$ & $\begin{array}{l}\text { Aulas Expositivas; Treinamento de } \\
\text { aplicação de mini exame do estado } \\
\text { mental; Roda de discussão sobre higiene } \\
\text { do sono. }\end{array}$ \\
\hline 8 & Agitação Psicomotora. & $\begin{array}{l}\text { Aula Expositiva; Treinamento prático de } \\
\text { contenção física; Aplicação de avaliação } \\
\text { e questionário de feedback. }\end{array}$ \\
\hline
\end{tabular}

Fonte: própria (2019). 
Quadro 2 - Temas abordados e metodologias utilizadas a Sala de Aula Invertida.

\begin{tabular}{|c|c|c|}
\hline Encontro & Temas Abordados & Metodologias \\
\hline 1 & $\begin{array}{l}\text { Introdução; Família na } \\
\text { perspectiva sistêmica; } \\
\text { Rede de Atenção } \\
\text { Psicossocial de } \\
\text { Uberaba; Diagnóstico } \\
\text { na Psiquiatria }\end{array}$ & $\begin{array}{l}\text { Aulas Expositivas; Discussão de caso } \\
\text { clínico; Aplicação de questionário } \\
\text { sociodemográfico e TCLE. }\end{array}$ \\
\hline 2 & $\begin{array}{l}\text { Antidepressivos, } \\
\text { benzodiazepínicos e } \\
\text { transtorno depressivo. }\end{array}$ & $\begin{array}{l}\text { Videoaulas (educação a distância) e leitura } \\
\text { de material complementar; Resposta de } \\
\text { questionamentos em grupo; Dinâmica } \\
\text { (crenças sobre psicofármacos); Estudo de } \\
\text { caso; Discussão de caso clínico. }\end{array}$ \\
\hline 3 & $\begin{array}{l}\text { Suicídio e transtornos } \\
\text { de ansiedade. }\end{array}$ & $\begin{array}{l}\text { Videoaulas (educação a distância) e leitura } \\
\text { de material complementar; Discussão de } \\
\text { casos clínicos; Estudo de caso; } \\
\text { Exposição de entrevistas gravadas com } \\
\text { atores simulando transtornos de ansiedade. }\end{array}$ \\
\hline 4 & $\begin{array}{l}\text { Esquizofrenia; } \\
\text { transtorno bipolar; } \\
\text { transtorno borderline; } \\
\text { autismo* e deficiência } \\
\text { intelectual*. }\end{array}$ & $\begin{array}{l}\text { Videoaulas (educação a distância) e leitura } \\
\text { de material complementar; Dinâmica } \\
\text { (preconceitos com transtorno mental); } \\
\text { Aulas expositivas. }\end{array}$ \\
\hline 5 & $\begin{array}{l}\text { Demência; insônia; } \\
\text { higiene do sono e } \\
\text { transtorno do déficit de } \\
\text { atenção e } \\
\text { hiperatividade*. }\end{array}$ & $\begin{array}{l}\text { Videoaulas (educação a distância) e leitura } \\
\text { de material complementar; Treinamento de } \\
\text { aplicação de mini exame do estado mental; } \\
\text { Roda de discussão sobre higiene do sono; } \\
\text { Aula Expositiva. }\end{array}$ \\
\hline 6 & Agitação Psicomotora. & $\begin{array}{l}\text { Videoaulas (educação a distância) e leitura } \\
\text { de material complementar; Treinamento } \\
\text { prático de contenção física; Aplicação de } \\
\text { avaliação e questionário de feedback. }\end{array}$ \\
\hline
\end{tabular}

Fonte: própria (2019). 


\subsection{Instrumentos de Coleta de dados}

No primeiro encontro de ambos os grupos foi aplicado um questionário elaborado pelos pesquisadores com questões relativas aos dados sociodemográficos (como sexo, idade, profissão); posse ou acesso a tecnologias com acesso à internet e interesse despertado pela temática (Apêndice 1).

Os questionários aplicados ao término dos cursos buscam avaliar dois elementos de aprendizagem da base da pirâmide de Kirkpatrick (Figura 1): a reação (ou satisfação) e o aprendizado resultantes dos módulos de ensino. Em 1967, Kirkpatrick propôs que programas de ensino sejam avaliados de acordo com quatro níveis hierárquicos. Partindo da base da pirâmide, cada nível de aprendizado é alicerce e requisito para se atingir a próxima etapa. Assim, é fundamental que a classe tenha tido uma reação e satisfação positivas ao curso de capacitação em saúde mental para que haja aprendizado. Esse por sua vez são fundamentais para que o profissional mude seu comportamento e reveja seus valores ao se deparar com as demandas psiquiátricas do cotidiano. Por fim, tal mudança é necessária para ocorrência de resultados positivos na população atendida pela equipe de saúde da família.

Figura 1- Pirâmide de Kirkpatrick

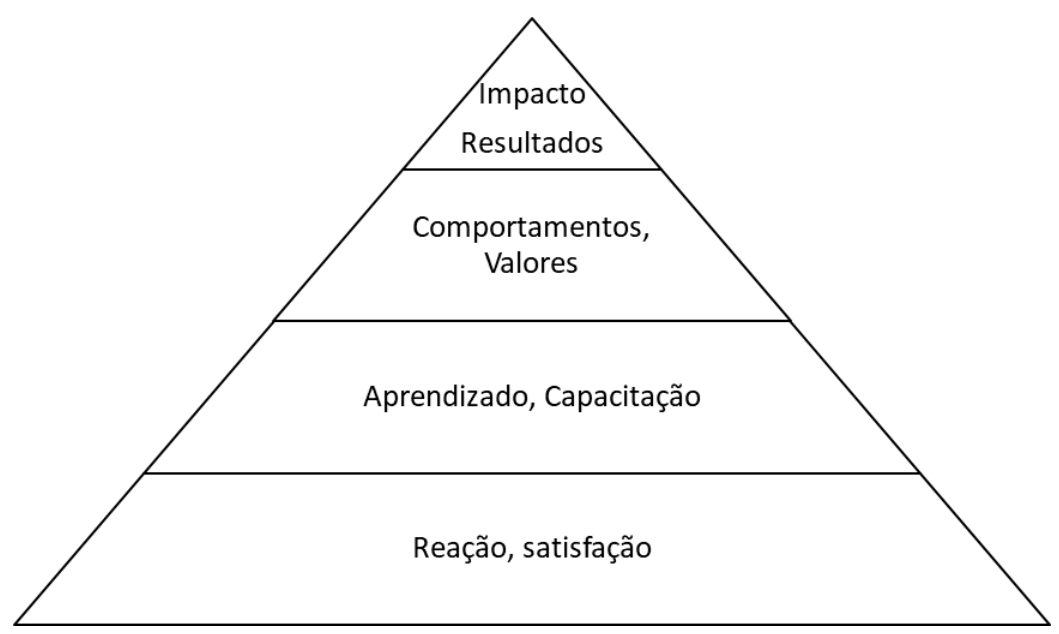

Fonte: Kirkpatrick, 1967.

Visando avaliar o aprendizado, foi aplicado ao final do curso uma prova de conhecimentos confeccionada na forma de questões abertas com respostas curtas e objetivas, de no máximo duas linhas (apêndice 2). Para cada questão havia uma lista específica de respostas aceitáveis para pontuação total e meia pontuação, de forma que qualquer resposta não inclusa na lista pré-estabelecida receberia pontuação zero. Tal lista de respostas foi 
elaborada com base nos resultados do curso piloto. As temáticas das questões foram depressão (questão 1), episódio psicótico e urgência psiquiátrica (questão 2), transtornos de ansiedade (questão 3), psicofarmacologia (questão 4) e higiene do sono (questão 5).

Além disso também foi aplicado um questionário de auto-avaliação (apêndice 3). Os quesitos desse questionário incluíram a própria percepção de preparo pré e pós curso sobre diversas temáticas a serem pontuadas por meio de escala Likert de 1 a 5 . Ademais continha duas questões abertas com o intuito que os participantes descrevessem algo significativo que aprenderam no curso e como ele poderia ser útil na prática profissional.

Visando avaliar a reação e satisfação das turmas de EP e SAI, foi realizado um questionário de satisfação e feedback (apêndice 4) que possuía perguntas fechadas em relação a qualidade de vários aspectos do curso, desempenho do professor e dos participantes. Duas questões abertas solicitaram uma relação dos aspectos positivos e negativos do curso.

Duas perguntas abertas adicionais foram dirigidas exclusivamente para participantes do curso de SAI: "O que você achou de ter parte do seu curso com aulas não presenciais?"; e "O que você achou da qualidade geral das videoaulas e textos suplementares?"

Todos os questionários foram analisados após aplicação de ambos cursos pelo autor do estudo.

\subsection{Análise dos resultados quantitativos}

Os dados quantitativos foram tabulados utilizando o programa Microsoft Office Excel ${ }^{\mathbb{R}}$ 2011. A análise estatística foi realizada utilizando o programa IBM SPSS statistics ${ }^{\circledR}$ versão 21.0. As variáveis categóricas binárias (sexo, posse de computador com acesso a internet e posse de celular com acesso a internet) foram analisadas com teste exato de Fisher, enquanto as variáveis categóricas com grupos maiores do que dois (escolaridade, profissão, frequência de acesso a internet, dentre outras) foram analisadas com teste de qui-quadrado de Pearson. $\mathrm{O}$ teste Kolmogorov-Smirnov foi aplicado para verificar a aderência da distribuição dos dados a distribuição normal no tocante às notas do teste de conhecimento. Por fim, o teste de comparação entre médias (ANOVA) foi utilizado para análise comparativa das variáveis contínuas (notas do teste de conhecimento e idade dos participantes).

\subsection{Análise dos resultados qualitativos}


Para a exploração das questões abertas foi utilizada a técnica de análise de conteúdo. De acordo com Elo e Kyngas (2008), a análise de conteúdo é uma forma de organização dos dados que pode ser usada tanto para dados qualitativos quanto para dados quantitativos, podendo ser realizada de maneira indutiva ou dedutiva.

Tendo em vista a problemática em estudo, elegeu-se a análise de conteúdo indutiva. Operacionalmente, a análise de conteúdo indutiva utilizada no presente estudo seguiu a proposta de Elo e Kyngas (2008), a qual foi composta por três fases principais: preparação, organização e elaboração de relatórios (resultados) do processo de análise.

A fase de preparação iniciou com a transcrição das respostas abertas no programa Microsoft Office Word ${ }^{\circledR} 2011$ e com a descrição das unidades de análise. Nas unidades de análise buscamos identificar, após exaustivas leituras, o sentido contido respostas dos participantes.

Depois de fazer o destrinchamento dos dados, a análise foi conduzida usando a abordagem indutiva (ELO; KYNGAS 2008). Assim, a fase de organização incluiu a codificação aberta com a criação de categorias e a abstração. A codificação aberta significa que notas foram escritas nas margens do texto enquanto se realizava a leitura. O material escrito foi lido novamente, e então novas notas foram realizadas ao longo do texto para descrever todos os aspectos do conteúdo. As notas foram então recolhidas, a partir das margens, para folhas de codificação (ELO; KYNGAS 2008).

Após o recolhimento das notas em folhas/listas de codificação, estas foram agrupadas com o objetivo de reduzir o seu número (sintetização dos dados), por meio de semelhanças e diferenças entre elas. Nesta etapa, as categorias começaram a ser geradas livremente.

De acordo com Dey (1993), a criação de categorias não é simplesmente reunir observações que são semelhantes ou afins, em vez disso, os dados devem ser classificados como "pertencentes" a um determinado grupo, e isso implica uma comparação entre esses dados e outras observações que não pertencem à mesma categoria. Desse modo, cada categoria foi nomeada de acordo com a característica do conteúdo. Categorias com eventos e incidentes semelhantes foram agrupadas em subcategorias, e subcategorias foram agrupadas em categorias principais. Esse processo chamado de abstração continuou na medida em que foi possível até a saturação, quando os temas começaram a se repetir e nenhum tema novo emergiu da análise.

Após a reunião das categorias foi realizada uma reunião para validação dos dados com uma "juíza" uma enfermeira mestre em psiquiatria que não participou da presente pesquisa em outros momentos. A escolha da "juíza" foi em relação principalmente para obtermos 
maior confiabilidade de que os dados seriam claros para outras pessoas que não necessariamente fazem parte do contexto estudado, mas que trabalham com questão de pesquisa.

\subsection{Aspectos Éticos}

Todos os participantes leram e assinaram em duas vias o Termo de Consentimento Livre Esclarecido (TCLE) (Apêndice 5) segundo a Resolução CNS 466/12 para pesquisas envolvendo seres humanos (Brasil, 2012). O projeto foi submetido, avaliado e aprovado pelo Comitê de Ética em Pesquisa do Hospital das Clínicas da Faculdade de Medicina de Ribeirão Preto - HCFMRP/USP (CAAE: 52841115.9.0000.5440 ). 


\subsection{Caracterização dos participantes}

\subsubsection{Número de participantes e distribuição das categorias profissionais}

O número total de participantes neste estudo foi de 134 profissionais, provenientes de 12 equipes de saúde da família do município de Uberaba.

O grupo que cursou o módulo de ensino presencial (EP) contou a presença de 89 profissionais. Destes, 19 (21\%) foram excluídos do estudo (18 por apresentarem menos de $75 \%$ de frequência e 1 por não ser profissional da ESF), resultando em 70 participantes para análise final. Já o grupo que cursou o módulo de ensino no formato de sala de aula invertida (SAI) contou com 82 profissionais dos quais 18 (22\%) foram excluídos (12 por apresentarem menos de $75 \%$ de frequência, 5 por não serem profissionais da ESF e 1 por não assinar o TCLE), resultando em 64 participantes.

Sobre a distribuição das categorias dos profissionais, no grupo EP haviam 17 (24\%) profissionais de ensino superior (dentistas, médicos e enfermeiros), 9 (13\%) de ensino técnico (agente de saúde bucal e técnico de enfermagem) e 44 (63\%) em cargo que exige formação até o ensino fundamental (agentes comunitários de saúde).

No grupo SAI, haviam 20 (29\%) profissionais de ensino superior, 10 (16\%) no ensino técnico e $35(55 \%)$ em cargo que exige apenas o ensino fundamental. Não houve diferença estatisticamente significativa entre os grupos no quesito de profissão exercida $(p=0,89)$. A distribuição dos profissionais de cada curso é mostrada no gráfico 1.

Gráfico 1 - Distribuição dos profissionais que cursaram ensino presencial (EP) (a esquerda) e ensino em sala de aula invertida (SAI) (a direita).

\section{Ensino Presencial}

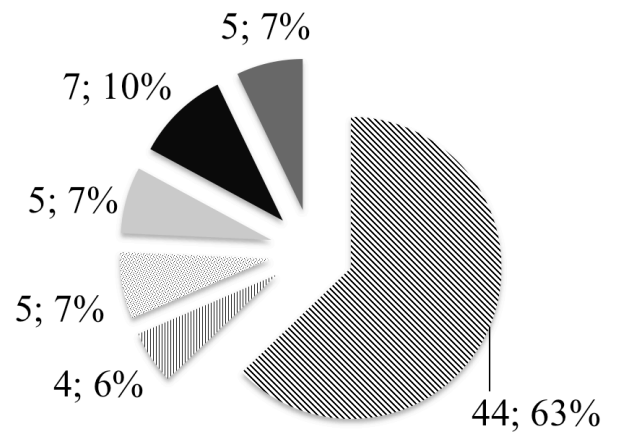

\section{Sala de Aula Invertida}

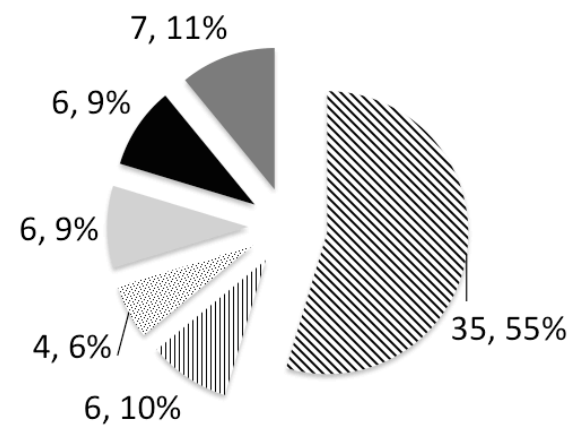

NAgente Comunitário de Saúde IIIII Técnico de Enfermagem
$\begin{array}{ll}\text { Agente de Saúde Bucal } & \text { Médico } \\ \text { - Dentista } & \text { Enfermeiro }\end{array}$

Fonte: própria (2019). 


\subsubsection{Perfil sociodemográfico}

As características sociodemográficas dos participantes e escolaridade estão apresentadas nas tabelas 1, 2, 3 e 4 . Não houve diferença estatisticamente significativa entre os grupos EP e SAI nos quesitos sexo $(p=0,33)$; idade média $(p=0,46)$ ou escolaridade dos participantes $(\mathrm{p}=0,24)$.

Tabela 1 - Características sociodemográficas dos participantes.

\begin{tabular}{lcc}
\hline \multicolumn{1}{c}{ Variável } & Ensino presencial (EP) & Sala de Aula Invertida (SAI) \\
\hline Sexo & Masculino: $7(10 \%)$ & Masculino: $3(5 \%)$ \\
& Feminino $: 63(90 \%)$ & Feminino: $61(95 \%)$ \\
Idade média & 42,7 anos & 41,9 anos \\
Idade mín. e máx. & 22 a 69 anos & 24 a 72 anos \\
\hline
\end{tabular}

Fonte: própria (2019).

Tabela 2 - Escolaridade por grupo profissional da turma de ensino presencial (EP)

\begin{tabular}{lcccc}
\hline & $\begin{array}{c}\text { Ensino } \\
\text { Fundamental }\end{array}$ & $\begin{array}{c}\text { Ensino } \\
\text { Médio }\end{array}$ & $\begin{array}{c}\text { Ensino } \\
\text { Superior }\end{array}$ & Pós Graduação \\
\hline ACS & $3(7 \%)$ & $27(63 \%)$ & $13(30 \%)$ & 0 \\
$\begin{array}{lcc}\text { Técnicos (Enf. e SB) } \\
\text { Médicos, Enfermeiros e }\end{array}$ & $1(11 \%)$ & $6(67 \%)$ & $2(22 \%)$ & 0 \\
\begin{tabular}{l} 
Dentistas \\
\multicolumn{1}{c}{ Total }
\end{tabular} & 0 & 0 & $2(12 \%)$ & $15(88 \%)$ \\
\hline
\end{tabular}

ACS: agente comunitário de saúde; Enf.: enfermagem; SB: saúde bucal

Fonte: própria (2019).

Tabela 3 - Escolaridade por grupo profissional da turma de sala de aula invertida (SAI)

\begin{tabular}{lcccc}
\hline & $\begin{array}{c}\text { Ensino } \\
\text { Fundamental } \\
\text { Completo }\end{array}$ & $\begin{array}{c}\text { Ensino Médio } \\
\text { (Completo ou } \\
\text { incompleto) }\end{array}$ & $\begin{array}{c}\text { Ensino Superior } \\
\text { (Completo ou } \\
\text { incompleto) }\end{array}$ & $\begin{array}{c}\text { Pós Graduação } \\
\text { (Completo ou } \\
\text { incompleto) }\end{array}$ \\
\hline ACS & $1(3 \%)$ & $28(80 \%)$ & $5(14 \%)$ & $1(3 \%)$ \\
Técnicos (Enf. e SB) & 0 & $7(70 \%)$ & $2(20 \%)$ & $1(10 \%)$ \\
Ensino superior & 0 & 0 & $2(11 \%)$ & $17(89 \%)$ \\
\hline \multicolumn{1}{c}{ Total } & $\mathbf{1 ( 1 \% )}$ & $\mathbf{3 5 ( 5 5 \% )}$ & $\mathbf{9 ( 1 4 \% )}$ & $\mathbf{1 9 ( 3 0 \% )}$ \\
\hline
\end{tabular}

Fonte: própria (2019). 
Tabela 4 - Comparação entre escolaridade dos participantes de cada grupo.

\begin{tabular}{lcccc}
\hline & $\begin{array}{c}\text { Ensino } \\
\text { Fundamental } \\
\text { Completo }\end{array}$ & $\begin{array}{c}\text { Ensino Médio } \\
\text { (Completo ou } \\
\text { incompleto) }\end{array}$ & $\begin{array}{c}\text { Ensino Superior } \\
\text { (Completo ou } \\
\text { incompleto) }\end{array}$ & $\begin{array}{c}\text { Pós Graduação } \\
\text { (Completo ou } \\
\text { incompleto) }\end{array}$ \\
\hline Ensino presencial & $4(6 \%)$ & $33(48 \%)$ & $17(24 \%)$ & $15(22 \%)$ \\
Sala de aula invertida & $1(1 \%)$ & $35(55 \%)$ & $9(14 \%)$ & $19(30 \%)$ \\
\hline
\end{tabular}

Fonte: própria (2019).

\subsubsection{Caracterização do acesso e uso da internet}

A frequência de acesso à internet e posse de meios para acesso à internet são apresentados nas tabelas 5 e 6 . Não houve diferença estatisticamente significativa entre os grupos quanto a frequência de acesso a internet $(\mathrm{p}=0,32)$, posse de computador com acesso a internet $(p=0,64)$ ou posse de celular com acesso a internet $(p=0,68)$.

Tabela 5 - Frequência de acesso à internet entre os profissionais participantes.

\begin{tabular}{lcc}
\hline $\begin{array}{c}\text { Frequência de acesso à } \\
\text { internet }\end{array}$ & $\begin{array}{c}\text { Ensino presencial } \\
\text { (EP) }\end{array}$ & $\begin{array}{c}\text { Sala de Aula Invertida } \\
\text { (SAI) }\end{array}$ \\
\hline Não respondeu & $1(1 \%)$ & 0 \\
Nunca ou $<1$ vez ao mês & $3(4 \%)$ & $7(12 \%)$ \\
1 a 4 dias por semana & $14(20 \%)$ & $8(13 \%)$ \\
$>5$ dias por semana & $52(75 \%)$ & $49(75 \%)$ \\
\hline
\end{tabular}

Fonte: própria (2019).

Tabela 6 - Posse de tecnologias com acesso a internet.

\begin{tabular}{lcc}
\hline \multicolumn{1}{c}{ Tecnologia } & $\begin{array}{c}\text { Ensino } \\
\text { presencial (EP) }\end{array}$ & $\begin{array}{c}\text { Sala de Aula } \\
\text { Invertida (SAI) }\end{array}$ \\
\hline Possui computador com acesso à internet & $58(83 \%)$ & $55(86 \%)$ \\
Possui celular/Tablet com acesso à internet & $65(93 \%)$ & $61(95 \%)$ \\
\hline
\end{tabular}

Fonte: própria (2019).

\subsection{Carga horária dos cursos}

A distribuição do tempo dedicado a atividades presenciais, seja no formato de aulas expositivas, metodologias ativas de ensino, ou atividades de ensino a distância é mostrada no gráfico 2. Ressalto que não houve conversão completa das aulas expositivas dialogadas em 
EAD por dois motivos. O primeiro é que o primeiro encontro de ambos cursos seguiu o formato tradicional, pois não seria razoável exigir preparo pré classe antes mesmo do primeiro encontro. $\mathrm{O}$ segundo motivo se deve às aulas com temática a escolha da turma terem mantido formado de auto expositiva.

Gráfico 2 - Horas de aula despendidas em cada grupo, de acordo com a estratégia de ensino adotada.

\section{Ensino Presencial}

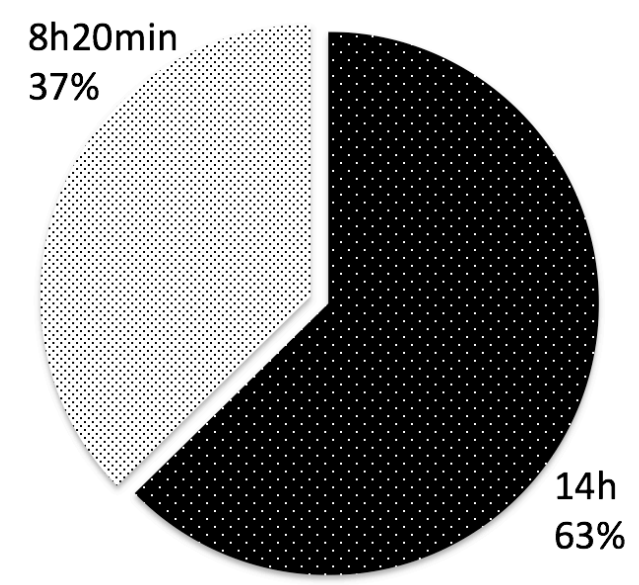

Aulas Expositivas " Ensino à Distância

\section{Sala de Aula Invertida}

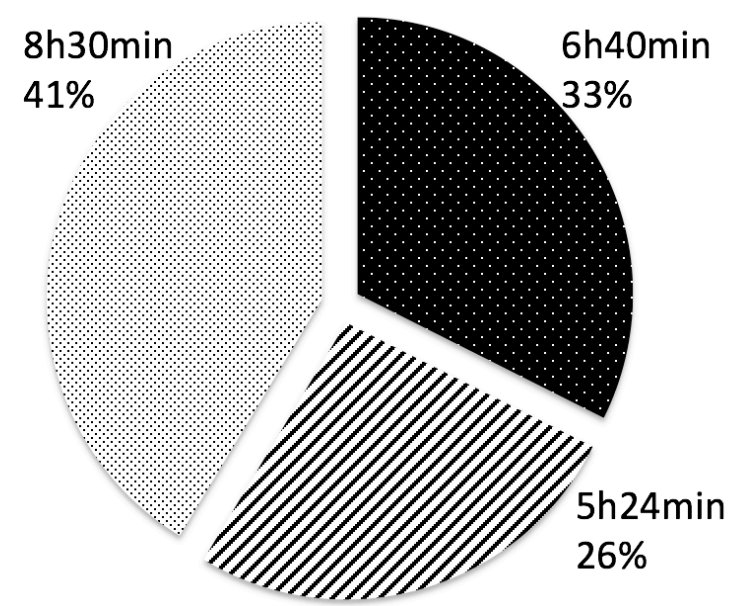

Metodologias Ativas

Fonte: própria (2019).

\subsection{Avaliação de desempenho de cada grupo após prova escrita}

Os resultados obtidos na avaliação teórica de conhecimento demonstraram associação estatisticamente significativa entre a nota e a profissão exercida, como mostra a tabela 7 e os gráficos 3 e 4 . Os profissionais de ensino superior tiveram nota média superior do que os ACS e profissionais de nível técnico $(\mathrm{P}<0,001)$. Contudo, as notas dos ACS e dos profissionais de nível técnico foram semelhantes entre si $(\mathrm{p}=0,96)$.

Os gráficos das notas obtidas pelo conjunto de participantes possuem distribuição normal tanto no EP $(p=0,39)$ quanto na SAI $(p=0,47)$. Não houve diferença estatisticamente significativa entre a nota média obtida pelo grupo EP e SAI $(p=0,13)$. 
Tabela 7 - Pontuação média obtida na prova de conhecimentos.

\begin{tabular}{ccc}
$\begin{array}{c}\text { Categoria } \\
\text { Profissional }\end{array}$ & $\begin{array}{c}\text { Ensino presencial } \\
\text { (EP) }\end{array}$ & $\begin{array}{c}\text { Sala de Aula Invertida } \\
\text { (SAI) }\end{array}$ \\
\hline Agente comunitário de Saúde & 5,1 & 5,0 \\
Profissionais de nível técnico & 4,5 & 5,7 \\
Profissionais de ensino superior & 7,5 & 7,7 \\
\hline Total & $\mathbf{5 , 6}$ & $\mathbf{5 , 9}$ \\
\hline
\end{tabular}

Obs: nota mínima $=0$ e nota máxima $=10$.

Fonte: própria (2019).

Gráfico 3 - Notas obtidas pelo conjunto de participantes nos dois modelos de ensino, presencial (esquerda) e sala de aula invertida (direita).
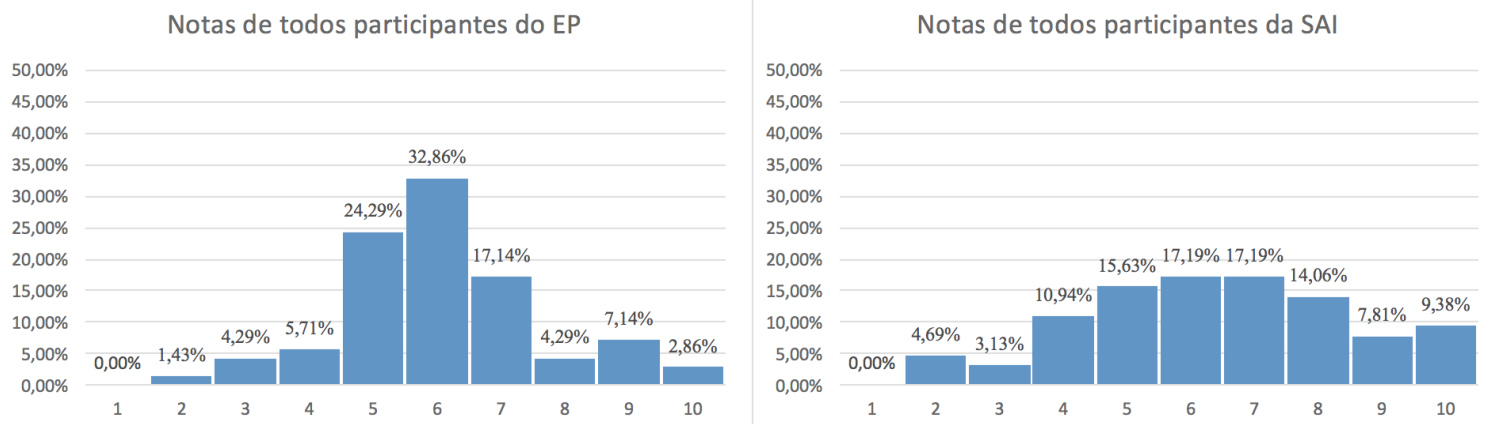

Fonte: própria (2019).

Gráfico 4 - Média e desvio padrão das notas dos ACS, profissionais de nível técnico e de ensino superior no ensino presencial (em azul) e na sala de aula invertida (em vermelho).

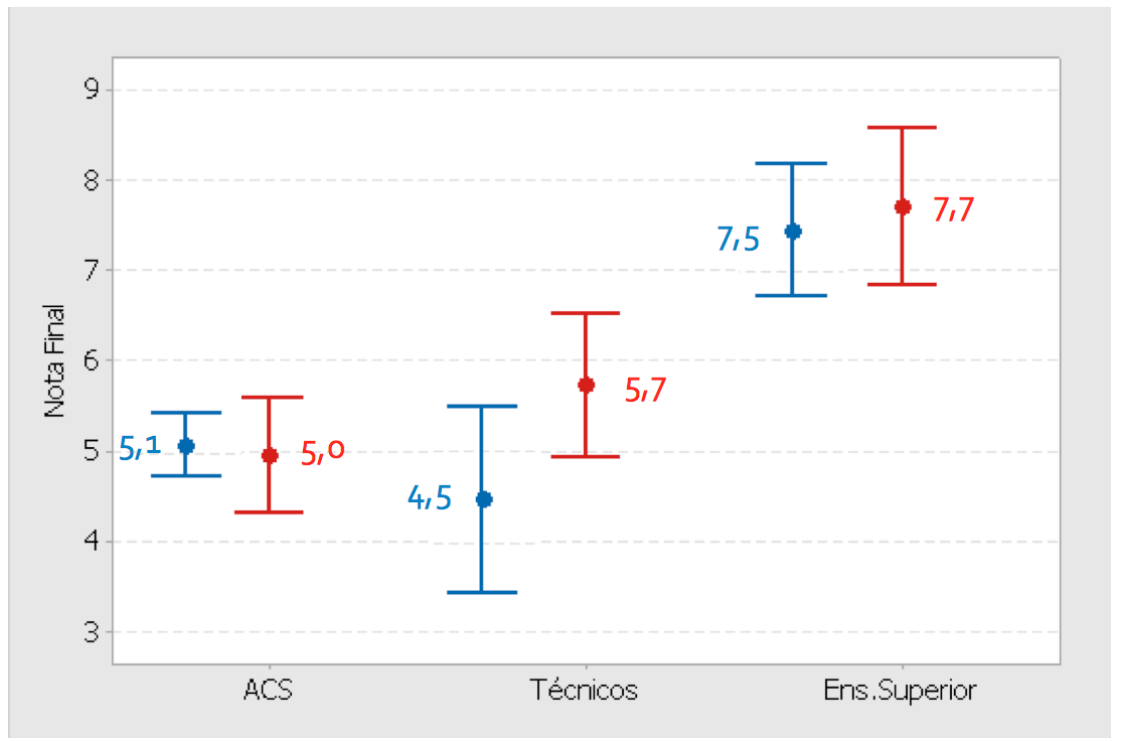

Fonte: própria (2019). 


\subsection{Auto avaliação de aprendizagem}

A auto avaliação incluiu questionamento sobre a percepção subjetiva de preparo antes de depois do curso, permitindo mensurar a percepção de ganho de conhecimento e confiança sobre seu preparo para lidar com as demandas de saúde mental. Os resultados são apresentados na tabela 8 .

Tabela 8 - Auto avaliação das turmas quando ao seu preparo para lidar com as demandas de saúde mental.

\begin{tabular}{|c|c|c|c|c|}
\hline \multirow{2}{*}{ Percepção do Profissional } & \multicolumn{2}{|c|}{$\begin{array}{c}\text { Ensino } \\
\text { presencial (EP) }\end{array}$} & \multicolumn{2}{|c|}{$\begin{array}{c}\text { Sala de aula } \\
\text { invertida (SAI) }\end{array}$} \\
\hline & $\begin{array}{c}\text { Pré } \\
\text { Curso }\end{array}$ & $\begin{array}{l}\text { Pós } \\
\text { Curso }\end{array}$ & $\begin{array}{c}\text { Pré } \\
\text { Curso }\end{array}$ & $\begin{array}{l}\text { Pós } \\
\text { Curso }\end{array}$ \\
\hline $\begin{array}{l}\text { 1- Me sinto despreparado (conhecimento e } \\
\text { habilidade) para lidar com esse tema. }\end{array}$ & $\begin{array}{c}33 \\
(50 \%)\end{array}$ & $\begin{array}{c}3 \\
(5 \%)\end{array}$ & $\begin{array}{c}20 \\
(34 \%)\end{array}$ & $\begin{array}{c}1 \\
(2 \%)\end{array}$ \\
\hline $\begin{array}{l}\text { 2- Me sinto com pouco conhecimento, } \\
\text { habilidade e preparo para lidar com esse tema. }\end{array}$ & $\begin{array}{c}20 \\
(30 \%)\end{array}$ & $\begin{array}{c}7 \\
(11 \%)\end{array}$ & $\begin{array}{c}22 \\
(38 \%)\end{array}$ & $\begin{array}{c}8 \\
(14 \%)\end{array}$ \\
\hline $\begin{array}{l}\text { 3- Me sinto com algum conhecimento, } \\
\text { habilidade e preparo para lidar com esse tema. }\end{array}$ & $\begin{array}{c}11 \\
(17 \%)\end{array}$ & $\begin{array}{c}35 \\
(53 \%)\end{array}$ & $\begin{array}{c}14 \\
(24 \%)\end{array}$ & $\begin{array}{c}27 \\
(47 \%)\end{array}$ \\
\hline $\begin{array}{l}\text { 4- Me sinto com conhecimento, habilidade e } \\
\text { preparo suficientes para lidar com esse tema. }\end{array}$ & $\begin{array}{c}2 \\
(3 \%)\end{array}$ & $\begin{array}{c}18 \\
(28 \%)\end{array}$ & $\begin{array}{c}2 \\
(3 \%)\end{array}$ & $\begin{array}{c}21 \\
(36 \%)\end{array}$ \\
\hline $\begin{array}{l}\text { 5- Me sinto muito competente para lidar com } \\
\text { esse tema. }\end{array}$ & 0 & $\begin{array}{c}2 \\
(3 \%)\end{array}$ & 0 & $\begin{array}{c}1 \\
(2 \%)\end{array}$ \\
\hline
\end{tabular}

Fonte: própria (2019).

É possível mensurar a variação da percepção de preparo resultante da intervenção através da subtração da pontuação de preparo pós curso menos a pontuação de preparo pré curso (tabela 9). Por exemplo: um participante que se sentia "despreparado" (pontuando 1) antes do curso e passou a se sentir "com algum conhecimento, habilidade ou preparo" (pontuando 3) após o curso teve uma variação de 2 pontos na escala utilizada. 
Tabela 9 - Variação da pontuação de percepção de preparo para lidar com as demandas de saúde mental antes e depois do curso.

\begin{tabular}{ccc}
\hline Variação & Ensino presencial (EP) & Sala de aula invertida (SAI) \\
\hline 0 & $7(11 \%)$ & $7(12 \%)$ \\
1 & $25(39 \%)$ & $30(52 \%)$ \\
2 & $29(45 \%)$ & $18(31 \%)$ \\
3 & $3(5 \%)$ & $2(3 \%)$ \\
4 & 0 & 0 \\
\hline
\end{tabular}

Fonte: própria (2019).

A segunda parte do questionário de auto avaliação continha duas perguntas abertas sobre a utilidade do curso e a significância dele. Como as respostas de ambas perguntas foram muito semelhantes, optamos por as agrupar em um mesmo conjunto de categorias: P1-A, P1B, P1-C, P1-D, P1-E e P1-F.

O tema de cada categoria foi: P1-A Aprendizado sobre psicofarmacologia; P1-B Percepção sobre a complexidade da saúde mental; P1-C Desenvolvimento da capacidade de reconhecer ou diagnosticar transtornos mentais; P1-D Construção da capacidade pessoal de abordar o usuário acometido por transtorno mental, P1-E Aprendizado sobre um ou mais transtornos mentais específicos e P1-F Valorizar e respeitar as queixas relacionadas à saúde mental.

\section{P1-A Aprendizado sobre psicofarmacologia (respostas que ressaltaram} principalmente algum aspecto relacionado a psicofarmacologia):

"As diferenças e as medicações das distintas classes de antidepressivos."

Médico 2 do grupo de EP.

"Apesar de não poder prescrever, a psicofarmacologia foi importante e esclarecedor para conhecer a atuação dos medicamentos."

Dentista 2 do grupo de SAI.

P1-B Percepção sobre a complexidade da saúde mental (respostas que ressaltaram principalmente mudanças da visão sobre saúde mental):

"A abrangência dos transtornos mentais na definição do cotidiano do indivíduo, família e meio."

Dentista 7 do grupo de EP. 
"Que saúde mental é um assunto sério e que requer muita atenção. Muitas coisas que achávamos ou tachávamos como frescura ou sem importância pode ser algo mais sério do que podemos pensar."

Agente comunitário de saúde 2 do grupo de SAI.

\section{P1-C Desenvolvimento da capacidade de reconhecer ou diagnosticar transtornos mentais (respostas que apontaram o desenvolvimento da capacidade de identificar transtornos mentais):}

"Identificar algumas doenças mentais para podermos encaminhar."

Dentista 2 do grupo de EP.

"O curso foi muito rico em conteúdo, aprendi a identificar as diferentes patologias e como encaminhá-las."

Agente comunitário de saúde 22 do grupo de SAI.

P1-D Construção da capacidade pessoal de abordar o usuário acometido por transtorno mental (resposta que descreveram percepção de maior preparo para lidar com as demandas de saúde mental):

"Aprendi a me dar melhor com os pacientes psiquiátricos pois tinha muito medo de chegar perto deles e a questão das medicações que consegui diferencial melhor."

Agente comunitário de saúde 23 do grupo de EP.

"Aprendi a identificar os riscos de suicídio e também aprendi formas de abordar o assunto para conversar $e$ orientar pacientes com necessidade de tratamento psiquiátrico. Não me sinto mais uma leiga no assunto de saúde mental."

Agente comunitário de saúde 17 do grupo de SAI.

P1-E Aprendizado sobre um ou mais transtornos mentais específicos (respostas que apontaram aprendizados relacionados a um ou mais transtornos mentais específicos):

"Foi fácil entender e absolver sobre, transtorno de ansiedade e depressão. Todos os temas foi de uma importância e aprendizados, mas os que eu gostei mais foram os dois citados acima."

Agente comunitário de saúde 10 do grupo de EP.

"Esquizofrenia: eu tinha várias dúvidas em relação esse assunto tenho irmão esquizofrênico depois do curso o meu 
convívio com ele melhorou bastante aprendi a entende melhor."

Agente comunitário de saúde 11 do grupo de SAI.

P1-F Valorizar e respeitar as queixas relacionadas à saúde mental (respostas que demonstram maior valorização e respeito com as queixas de portadores de transtornos mentais):

"A respeitar as pessoas com problemas, pois na maioria das vezes não são entendidas por familiares."

Agente comunitário de saúde 16 do grupo de EP..

"Antes de rotular, parar, pensar, discutir o assunto, pedir ajuda. Dividir as responsabilidades com todos os membros da equipe. Principalmente respeitar a dificuldade de cada um."

Agente comunitário de saúde 10 do grupo de SAI.

\subsection{Feedback sobre o curso}

O feedback sobre a qualidade curso foi avaliado através de preenchimento de tabela de satisfação (seguindo escala Likert) e questões abertas. Foram obtidos níveis elevados de aprovação em ambas modalidades de curso, como mostra a tabela 10.

Tabela 10- Número e porcentagem de participantes que avaliaram o quesito como bom ou muito bom

\begin{tabular}{lcc}
\hline \multicolumn{1}{c}{ Quesito } & Ensino presencial (EP) & Sala de Aula Invertida (SAI) \\
\hline Pertinência do Conteúdo & $64(91 \%)$ & $59(100 \%)$ \\
Estratégias de Ensino & $65(93 \%)$ & $60(98 \%)$ \\
Desempenho do Professor & $66(97 \%)$ & $58(98 \%)$ \\
Sua participação & $44(66 \%)$ & $44(72 \%)$ \\
Videoaulas & - & $43(86 \%)$ \\
Leitura complementar & - & $60(98 \%)$ \\
\hline
\end{tabular}

Fonte: própria (2019).

As duas perguntas abertas sobre feedback do curso questionaram quais os aspectos mais positivos do curso (aqueles que deveriam ser mantidos em futuras versões do curso) e quais os aspectos que ainda poderiam ser aprimorados e que precisariam ser revisados no futuro. As respostas mais comuns sobre a questão P3, que solicitava destaque aos aspectos mais positivos do curso, foram divididas nas categorias P3-A, P3-B, P3-C, P3-D e P3-E. As temáticas de tais categorias foram: P3-A Didática e desempenho do professor; P3-B 
Metodologias de ensino empregadas; P3-C Temas abordados; P3-D Participação de toda equipe da Estratégia de Saúde da Família; P3-E Material para ensino a distância.

P3-A Didática e desempenho do professor (respostas que destacaram aspectos positivos sobre desempenho do professor):

"Aulas bem planejadas, o professor deu melhor de si para com todos, quando tínhamos dúvidas o professor tentou tirá-las com bastante sabedoria e paciência."

Agente comunitário de saúde 25 do grupo de EP.

"Ótima didática e dinâmica para trabalhar com turma bastante heterogênea. Material didático claro e objetivo (tanto impresso como audiovisual). Professor acessivel para esclarecimento de dúvidas e discussão de casos extra classe."

Dentista 4 do grupo de SAI.

P3-B Metodologias de ensino empregadas (respostas que ressaltaram uma ou mais metodologia de ensino utilizada):

\author{
"Os estudos de caso, as dinâmicas propostas." \\ Enfermeiro 3 do grupo de EP. \\ "As vídeo aulas e dinâmicas." \\ Agente comunitário de saúde 3 do grupo de SAI.
}

P3-C Temas abordados (respostas que apontaram o conteúdo abordado no curso):

\author{
"Os tópicos escolhidos e o método de dar aula." \\ Dentista 1 do grupo de EP. \\ "Os temas propostos foram excelentes." \\ Dentista 1 do grupo de SAI.
}

P3-D Participação de toda equipe da Estratégia de Saúde da Família (respostas que destacam aspectos relacionados a presença da equipe completa):

"Compartilhamento de experiências e vivencias, interação com outras ESF."

Dentista 7 do grupo de EP.

"Temas. Professor. Estudos de caso. Todos os profissionais da equipe de ESF." 
Naturalmente respostas mencionando material para estudo a distância só foram feitas na turma do curso de sala de aula invertida.

\section{P3-E Material para ensino a distância (respostas que destacaram as videoaulas ou textos didáticos): \\ "As vídeo aulas e dinâmicas." \\ Agente comunitário 3 do grupo de EP. \\ "Professor muito bom e preparado. Conteúdo rico. Material suficiente p/ um bom preparo."}

Agente comunitário 31 do grupo de SAI.

As respostas mais comuns sobre o questionamento a respeito dos aspectos que poderiam ser aprimorados ou modificados (questão P4) foram divididos nas categorias P4-A, P4-B, P4-C, P4-D, P4-E, P4-F e P4-G. As respostas em comum de ambos os grupos (ensino presencial e sala de aula invertida) incluíram as seguintes categorias: P4-A Necessidade de maior carga horaria ou continuação do curso, P4-B Separação da turma por categoria profissional, P4-C Queixa sobre local de ensino e/ou falta de transporte e P4-D Mudança de dia ou horário.

P4-A Havia necessidade de maior carga horaria ou continuação do curso (respostas em que se solicitava mais tempo de curso ou continuidade do mesmo):

"Mais tempo de aula, o assunto além de muito importante está presente no nosso dia a dia e na vida particular da maioria."

Agente comunitário de saúde 11 do grupo de EP.

"As aulas poderiam ser estendidas para mais horas, o assunto é muito extenso e merece mais detalhes a serem discutidos."

Enfermeira 2 do grupo de SAI.

P4-B Separação da turma por categoria profissional (respostas que sugeriram divisão da turma por profissão):

"Separação dos profissionais por área de atuação - ACS não tem o mesmo interesse que profissionais de curso superior. Maior carga horaria." 
"Divisão da turma de acordo com o nível de escolaridade"

Dentista 2 do grupo de SAI.

P4-C Queixa sobre local de ensino e/ou falta de transporte (respostas que traziam queixas sobre a distância do local do curso, dificuldade de locomoção ou sobre o espaço físico da sala de aula):

"Local mais próximo das unidades de saúde. Sala mais ampla e arejada. Ajuda de custo para os participantes."

Agente de saúde bucal 4 do grupo de EP.

"Seguimento do curso. Obs: o espaço poderia ser melhor. Local muito quente e sem ventilação."

Agente comunitário de saúde 22 do grupo de SAI.

P4-D Mudança de dia ou horário (respostas que sugerem alteração do dia da semana e horário de realização do curso):

"O Horário que foi dado."
Agente de saúde bucal 6 do grupo de EP.
"Mudar o dia (na sexta as pessoas ficam muito
agitadas)."

Médico 3 do grupo de SAI.

Algumas sugestões de aprimoramento somente ocorreram na turma de ensino presencial (P4-E Solicitação de maior atenção às perguntas realizadas em sala de aula; P4-F Solicitação de mais metodologias ativas de ensino e P4-G Solicitação de material individual) enquanto queixas sobre o material de ensino a distância só puderam ocorrer na turma de sala de aula invertida (P4-H Queixas relacionadas ao material de ensino a distância).

P4-E Solicitação de maior atenção às perguntas realizadas em sala de aula (respostas que apontaram necessidade de maior abertura para perguntas dos participantes):

"Mudar a estratégia para solicitar silencio e atenção. Melhorar e responder na hora as dúvidas. Valorização das questões levantadas baseadas nas experiências dos outros."

Dentista 7 do grupo de EP. 
"Responder as perguntas quando for questionado e não deixa-las pra depois"

Agente comunitário de saúde 39 do grupo de EP.

P4-F Solicita mais metodologias ativas de ensino (respostas que solicitaram maior uso de alguma forma de metodologia ativa de ensino):

"Mais vivencia de casos."

Dentista 2 do grupo de EP.

"Participação c/ mais dinâmicas pois deu um pouco de sono; por causa do horário."

Agente comunitário de saúde 36 do grupo de EP.

P4-G Solicitação de material individual (respostas que solicitaram material individual de estudo):

"Poderíamos ter acesso sobre o assunto antes de velo em sala de aula. Para melhor acompanhar as aulas ministradas."

Agente comunitário de saúde 16 do grupo de EP.

"Material individual p/ melhor acompanhamento"

Agente comunitário de saúde 19 do grupo de EP.

\section{P4-H Queixas relacionadas ao material de ensino a distância (respostas que apontaram problemas relacionados ao material de ensino a distância):}

"Melhorar o som das vídeo aulas à distância"

Agente comunitário de saúde 10 do grupo de SAI.

"Não sei para muitos, mas para mim tarefa de casa não é muito legal. Não sou muito boa com o relógio. Aproveito muito mais os conteúdos na sala de aula interagindo com professores e colegas"

Agente comunitário de saúde 17 do grupo de SAI.

Uma das perguntas abertas que esteve presente apenas no questionário dos participantes da sala de aula invertida (P5) solicitou feedback sobre a utilização de materiais de ensino à distância. Suas respostas mais comuns foram categorizadas em P5-A, P5-B, P5-C e P5-D. Os temas encontrados foram: P5-A Queixa de falta de tempo para realizar ensino a distância; P5-B Atribui valor como material de revisão; P5-C Atribui valor como material de aprofundamento; P5-D Atribui papel complementar; conforme mostram os exemplos abaixo. 
P5-A Queixa de falta de tempo para realizar ensino a distância (respostas que destacaram a dificuldade de conseguir tempo para utilizar o material de ensino a distância):

"Difícil. Não temos muito tempo para estudar em casa devido a extensa carga horaria de trabalho. Ainda temos que estudar outros temas para trabalhar com a equipe $e$ comunidade."

Enfermeira 4 do grupo de SAI.

"Não gosto, porque não tenho muito tempo para ver e ler, mais é interessante ter os textos p/ tirar dúvidas isto p/mim, mas é um complemente para que tem tempo $\mathrm{p} / \mathrm{ver}$ e ler"

Agente de saúde bucal 1 do grupo de SAI.

P5-B Atribui valor como material de revisão (respostas que apontaram o material de ensino a distância como forma de revisão do conteúdo):

"Muito bom. Dá oportunidade de rever o conteúdo sempre que necessário.”

Dentista 1 do grupo de SAI.

"Considerei muito bom pois dá possibilidade de consultas posteriores."

Dentista 4 do grupo de SAI.

P5-C Atribui valor como material de aprofundamento (respostas que apontaram o material de ensino a distância como forma de aprofundamento do conteúdo):

"Ótimo para ampliar os conhecimentos, tirar dúvidas, ter a disposição material sobre o assunto que pode ser consultado a qualquer comento."

Enfermeira 5 do grupo de SAI.

"Interessante pois é possivel aprofundar nos conteúdos."

Agente comunitário de saúde 28 do grupo de SAI.

P5-D Atribui papel complementar (respostas que ressaltam o material de ensino a distância como complementares ao ensino em sala de aula):

"Achei bom, pois um complementa o outro."

Agente comunitário de saúde 23 do grupo de SAI.

"São complementares. Importantes para agregar conhecimento." 
A segunda pergunta aberta exclusiva para a turma de SAI (P6) questiona a qualidade do material de ensino a distância, e suas respostas foram divididas nas categorias P6-A, P6-B e P6-C. Os temas das categorias foram: P6-A Qualidade geral boa ou ótima; P6-B Considera o material didático, objetivo e com linguagem acessível e P6-C Não despertou interesse; conforme mostram os exemplos abaixo:

P6-A Qualidade geral boa ou ótima (respostas que apontam a qualidade do material de ensino a distância como boa ou ótima):

"Muito bom todo o material. Montei uma pasta com todo o material e ficará disponivel para todos os profissionais que atuam na minha unidade."

Enfermeira 5 do grupo de SAI.

"Gostei muito das vídeo aulas, os textos foram ótimos de um bom conteúdo."

Agente comunitário de saúde 23 do grupo de SAI.

P6-B Considera o material didático, objetivo e com linguagem acessível (respostas que descreveram o material de ensino a distância como didático, objetivo ou com linguagem acessível):

"Muito bom, bem didáticos e de uma linguagem simples que todos possam entender."

Agente de saúde bucal 2 do grupo de SAI.

"Material de excelente qualidade. Claro e objetivo com referencias bibliográficas para o aluno que desejar aprofundar mais no tema."

Dentista 4 do grupo de SAI.

\footnotetext{
P6-C Não despertou interesse (respostas destacando falta de interesse pela utilização do material de ensino a distância):

"A objetividade com certeza foi das melhores, didática acredito que também deve ter ficado boa, levando em consideração a dedicação, conhecimento e desempenho do professor nas aulas, mas não despertou meu interesse nos poucos que comecei a assistir. Quanto a relevância não pude avaliar pois não assisti (ainda mas é bom saber só caso eu precise relembrar)."

Agente comunitário de saúde 17 do grupo de SAI.
} 
"Objetivas, conteúdo ideal o áudio estava muito baixo (talvez problema no meu pc), as minhas acs tiveram pouco interesse, mas eu gostei muito. Complementa os estudos."

Enfermeira $4 \mathrm{~d}$ do grupo de SAI.

\subsection{Assiduidade do uso de material de ensino a distância}

Apesar das avaliações positivas quando ao material utilizado no ensino a distância da turma de sala de aula invertida, a assiduidade auto relatada sobre o uso do material foi baixa, como mostram as tabelas 11 e 12 .

Tabela 11- Assiduidade no uso do material de leitura complementar.

\begin{tabular}{lcccc}
\hline & Não respondeu & $<50 \%$ & 50 a $75 \%$ & 75 a $100 \%$ \\
\hline ACS & 5 & $15(50 \%)$ & $11(37 \%)$ & $4(13 \%)$ \\
Nível técnico & 0 & $5(50 \%)$ & $5(50 \%)$ & 0 \\
Nível superior & 1 & $8(44 \%)$ & $7(39 \%)$ & $3(17 \%)$ \\
\hline Total & $\mathbf{6}$ & $\mathbf{2 8 ( 4 8 \% )}$ & $\mathbf{2 3 ( 4 0 \% )}$ & $\mathbf{7 ( 1 2 \% )}$ \\
\hline
\end{tabular}

Fonte: própria (2019).

Tabela 12- Assiduidade no uso das videoaulas.

\begin{tabular}{lcccc}
\hline & $\begin{array}{c}\text { Não } \\
\text { respondeu }\end{array}$ & $<50 \%$ & 50 a $75 \%$ & 75 a $100 \%$ \\
\hline ACS & 4 & $20(65 \%)$ & $6(19 \%)$ & $5(16 \%)$ \\
Nível Técnico & 0 & $7(70 \%)$ & $3(30 \%)$ & 0 \\
Nível superior & 1 & $9(50 \%)$ & $6(33 \%)$ & $3(17 \%)$ \\
\hline Total & $\mathbf{5}$ & $\mathbf{3 6 ( 6 1 \% )}$ & $\mathbf{1 5 ( 2 5 \% )}$ & $\mathbf{8 ( 1 4 \% )}$ \\
\hline
\end{tabular}

Fonte: própria (2019). 
Os dois grupos estudados tiveram características sociodemográficas semelhantes, como número de participantes (70 no EP e 64 na $\mathrm{SAI})$; proporção entre sexos $(90 \%$ feminino no EP e 95\% feminino na SAI) e idade média (42,7 anos no EP e 41,9 anos na SAI). Tais semelhanças ocorreram a despeito dos participantes não terem sido formalmente randomizados, mas sim escolhidos pela diretoria de atenção básica da secretaria de saúde do município de Uberaba.

A idade média em torno dos quarenta anos e o grande predomínio de integrantes do sexo feminino encontrados neste estudo é evidenciado também em outras pesquisas (ZANETTI, 2010; LIMA, 2016). Esse perfil feminino deve ser levado em conta ao se planejar o horário e duração dos encontros presencias do curso, pois muitas dessas mulheres precisam conciliar seu trabalho com afazeres domésticos, como preparo do almoço ou transporte dos filhos para a escola.

Em relação a escolaridade dos ACS, apenas 19,24\% possuíam ensino superior completo ou incompleto. Esta porcentagem fica abaixo da encontrada em um outro estudo realizado na Paraíba, onde essa taxa era de 35\% $(n=348)$ (MUSSE, 2014). Tal dado aponta para a necessidade de se confeccionar material didático com linguajar e detalhamento técnico apropriados para essa categorial profissional.

A frequência de acesso à internet em ambos os grupos foi alta, com 95\% dos participantes acessando a internet ao menos uma vez por semana no grupo de EP e $88 \%$ na SAI. Além disso ao menos $93 \%$ dos participantes de cada grupo possuíam um dispositivo próprio com acesso a internet. Através desse dado pode-se inferir que a maioria dos participantes tem acesso a recursos tecnológicos que permitem a utilização de metodologias de ensino a distância. Ainda assim é preciso desenvolver estratégias para não excluir a minoria sem acesso à internet, como inclusão de material impresso ou uma solução citada por uma ACS participante da SAI "Foi ótimo pelo menos $p /$ mim que não tenho tempo $p$ / ver em casa, porque a enfermeira do nosso PSF colocava sempre o vídeos, como educação continuada."

O feedback sobre a qualidade do curso, primeiro elemento da pirâmide de Kirkpatrick, foi predominantemente positivo em ambas modalidades de ensino, havendo ao menos $86 \%$ de avaliações positivas, como mostrado no quadro 3. Entretanto, algumas diferenças podem ser percebidas nas respostas abertas fornecidas pelos participantes sobre o que poderia ser aprimorado no curso. Somente a turma de EP trouxe queixas demandando maior atenção às perguntas da classe, maior utilização de metodologias ativas de ensino e solicitando material 
individual. É possível que essas queixas ocorreram em consequência da maior carga horaria teórica realizada na forma de aula expositiva dialogada (gráfico 1), uma técnica de ensino com menor interação educador-estudante em comparação com as metodologias ativas de ensino. Vale ressaltar que tais diferenças somente puderam ser identificadas graças à inclusão de elemento qualitativo neste estudo, pois passariam despercebidas em um projeto unicamente quantitativo.

Outro dado importante revelado nas respostas abertas é que a opção pelo ensino com toda equipe da ESF foi tanto elogiada como criticada, como pode-se observar nas categorias P3-D e P4-B. Realizar capacitação de toda ESF simultaneamente traz desafios por tornar o público muito heterogêneo, havendo participantes com diversos níveis de escolaridade e conhecimento prévio. Além disso diferentes médicos, enfermeiros e dentistas podem possuir diversos níveis de conhecimento, atitude e habilidade em relação ao cuidado de transtornos mentais (GASK, 2013). No entanto, existe um ganho enorme quando o curso é oferecido para toda a equipe pois assim ele é trabalhado como na vida real, em que o paciente é visto e cuidado por pessoas com formações distintas e complementares.

Ademais a presença de todos profissionais estimula e valoriza o trabalho multi- e interprofissional, ressalta a importância da atuação de cada membro da ESF e permite integrar experiências e saberes entre os membros da equipe. A atuação multiprofissional para cuidado em saúde mental é preconizada pelo ministério da saúde do Brasil, como colocado no Guia Prático de Matriciamento em Saúde Mental:

"É muito importante que os profissionais da atenção primária - agentes de saúde, auxiliares de enfermagem, odontólogos, médicos, enfermeiros e outros - estejam convencidos de que são capazes de oferecer cuidados em saúde mental." (CHIAVERINI 2011)

A maioria dos estudos encontrados sobre educação em saúde mental para atenção básica foi realizada exclusivamente com a categoria médica (THOMPSON, 2000; ELIZABETH, 2001; VALENTINI, 2004; LEVAV, 2005; ZAKROYEVA, 2008; LAM, 2015). Além disso, a vários estudos tiveram enfoque sobre desfechos como aumento do diagnóstico e prescrição de antidepressivos (LIN, 1997; THOMPSON, 2000; ELIZABETH, 2001; VALENTINI, 2004; TITUS, 2004; GONÇALVES, 2012), não se preocupando em avaliar diferentes metodologias de ensino na capacitação. Essa avaliação é fundamental, como apontado por um artigo de Gask:

"Precisamos considerar não somente "O QUÊ" deveríamos estar tratando na instrução, ensino e formação de médicos de família a respeito da depressão, mas também, talvez ainda mais 
crucial, "COMO" isso deve ser abordado e executado". (GASK, 2013)

Uma das vantagens do ensino utilizando a estratégia de sala de aula invertida é justamente a possibilidade de confecção de material de ensino a distância individualizado. Assim pode-se adequar a linguagem, o tipo e o aprofundamento do conteúdo de acordo com a categoria profissional, de forma que o material não seja demasiado complexo para os ACS e profissionais de nível técnico e nem superficial demais para os profissionais de ensino superior, como foi feito neste projeto.

Tanto as videoaulas quanto os textos de leitura suplementar tiveram boas avaliações quantitativamente ( 86 e $98 \%$ de avaliações positivas, respectivamente) e qualitativamente, como mostram as respostas abertas apresentadas nas categorias P6-A e P6-B. Além disso vários participantes ressaltaram a importância do uso de material de $\mathrm{EAD}$, como mostram as respostas abertas apresentadas nas categorias P5-B, P5-C e P5-D. No entanto, os resultados sobre o uso do EAD na turma de SAI mostraram uma incongruência nas repostas dos avaliados.

Apesar de tais avaliações positivas, a assiduidade na leitura dos textos suplementares e visualização das videoaulas ficou aquém do desejado, como mostram as tabelas 10 e 11 . Possivelmente o motivo para essa má adesão seja a falta de tempo (como alegado na categoria P5-A) e falta de interesse (como relatado na categoria P6-C). Ademais, os encontros presenciais foram realizados durante o expediente de trabalho dos participantes, enquanto o preparo pré classe com material EAD precisava ser utilizado durante o tempo livre. A baixa assiduidade no uso do material EAD também foi um desafio encontrado em uma pesquisa conduzida por Heitz utilizando a SAI na graduação médica, a qual mostrou que $31 \%$ dos participantes não engajaram no preparo pré classe (HEITZ, 2015).

Ademais, houve maior adesão ao uso do material impresso do que nas videoaulas. Talvez isto seja um reflexo da familiaridade e, consequentemente, preferência do público com material de ensino tradicional.

O aprendizado obtido em cada grupo (segundo elemento da pirâmide de Kirkpatrick) foi semelhante, havendo discreta vantagem sem significância estatística favorecendo a sala de aula invertida (média da nota final 5,6 em 10 no ensino presencial e 5,9 na sala de aula invertida). Chama atenção o fato do desempenho obtido ser semelhante a despeito da baixa assiduidade no uso do material EAD. Possivelmente o aprendizado daqueles que não leram os textos e não assistiram as vídeoaulas ocorreu na pelo aprendizado pelos pares ("peer learning) nas atividades em grupo realizadas em sala de aula. 
JESEN et al (2015) realizou um estudo quase-experimental comparando educação presencial que utilizou metodologias ativas de ensino com a sala de aula invertida. Não houve diferenças entre o aprendizado ou satisfação entre as turmas, levando os autores a concluir que o uso de metodologias ativas, e não o uso híbrido de ensino a distância, que é responsável pelos ganhos da sala de aula invertida quando esta é comparada com o ensino tradicional. Esses achados são compatíveis com os do presente estudo, uma vez que a baixa adesão ao uso do material EAD sugere que os ganhos dos participantes ocorreram durante os encontros presenciais.

Um dado surpreendente quanto à nota obtida pelos participantes foi referente ao desempenho dos profissionais de nível técnico. Em ambos grupos sua nota foi mais próxima à obtida pelos agentes comunitários de saúde do que pelos profissionais de ensino superior, como mostra a tabela 8 e os gráficos 12 e 13. Isso sugere essa categoria profissional deve ter conteúdo de ensino a distância preparado com menor exigência de conhecimentos prévios.

A percepção subjetiva de aumento de preparo para lidar com as demandas de saúde mental foi predominantemente positiva, com ao menos $88 \%$ dos participantes de cada grupo referindo ganho com o curso. Tal ganho é fundamental, especialmente porque a grande maioria dos participantes de ambos grupos possuíam percepção de despreparo pessoal para lidar com as demandas de saúde mental $(80 \%$ se consideravam com pouco ou nenhum preparo no EP e $72 \%$ na SAI).

Já as respostas das perguntas P1 e P2 mostram relatos sobre ganhos técnicos (como aumento de conhecimento sobre transtornos mentais específicos e psicofarmacologia), aumento de auto suficiência (aumento da capacidade de reconhecer e abordar usuários acometidos por transtornos mentais) e humanização (valorização e percepção da complexidade de queixas relacionadas à saúde mental). Isso demonstra que tanto no EP quanto na SAI ocorreram ganhos que vão além da pura memorização de dados técnicos sobre a temática, o que é fundamental para promover mudança de atitude na prática profissional.

Este estudo possui várias limitações. Primeiramente não foi possível randomizar os participantes já que isso implicaria em dividir as equipes de saúde da família e prejudicar o funcionamento da unidade básica de saúde. Foi optado por não realizar pré teste de conhecimentos no início dos cursos uma vez que isso poderia prejudicar o vínculo e a adesão dos participantes. Por fim, este estudo não avalia os últimos elementos da pirâmide de Kirkpatrick: se a intervenção resulta em mudanças nos comportamentos e valores dos participantes e se tal mudança tem impacto positivo no cuidado em saúde mental. 
Por outro lado, algumas particularidades conferem potencialidades a esta pesquisa. Em primeiro lugar, os cursos foram realizados com a participação de toda equipe de saúde da família, e não com apenas uma categoria profissional como ocorreu na maioria das demais pesquisas sobre educação em saúde mental. A respeito do uso da metodologia de sala de aula invertida, a maioria das publicações realizadas até o momento foram realizadas dentro do meio acadêmico, enquanto este estudo avaliou a aplicabilidade deste método com profissionais formados e atuantes. $\mathrm{O}$ uso de um grupo controle permite inferir com mais precisão sobre as particularidades da SAI. As atividades práticas realizadas em ambos grupos foram semelhantes e contaram com o mesmo instrutor, reduzindo as variáveis que poderiam influenciar nos resultados. Por fim, o elemento qualitativo, realizado através de questões abertas, enriquece a pesquisa e confere insights que não ocorreriam em uma pesquisa unicamente quantitativa. 
Houve grande heterogeneidade dos participantes quanto a profissão e escolaridade, o que reforça a necessidade de utilização de estratégias de ensino que busquem a individualização do aprendizado.

O perfil sociodemográfico de ambos os grupos foi semelhante, sem diferença estatisticamente significativa em nenhum quesito analisado, tornando improvável a existência de viés de seleção e trazendo confiabilidade às comparações de resultados de um grupo com o outro.

Ambas estratégias de ensino proporcionaram resultados semelhantes na prova de conhecimentos e na percepção subjetiva de aprendizagem, evidenciando que, neste aspecto, a nova metodologia de ensino (SAI) é ao menos tão eficaz quanto a abordagem tradicional (EP). Em ambos cursos houve diferença estatisticamente significativa entre o desempenho dos profissionais de nível superior quando comparados com os profissionais de nível técnico e agentes comunitários de saúde.

Ambas estratégias de ensino foram bem avaliadas pelos participantes quanti e qualitativamente, mostrando que, neste aspecto, a SAI é ao menos tão bem percebida quando o EP.

Comparado ao EP, a SAI produziu resultados semelhantes em termos de aprendizagem e satisfação, ofereceu maior flexibilidade ao aprendiz e utilizou menor carga horária presencial. Isso é relevante especialmente quando necessário realizar capacitação em saúde mental para várias equipes de saúde da família com disponibilidade de tempo limitada. 
1. ANAStASIOU, L.G.C.; ALVES, L.P. Processos de Ensinagem na Universidade. Santa Catarina: Univille, 2012. 145p.

2. ATHIÉ, $\mathrm{K}$ et al. Perceptions of health managers and professionals about mental health and primary care integration in Rio de Janeiro: a mixed methods study. BMC Mental Health Services Research 16.532, 2016.

3. BRASIL. Saúde Mental no sus: cuidade em liberdade, defesa de direitos e rede de atenção psicossocial. Brasília, ministério da saúde, 2016.

4. BOLELLA, VR; CESARETTI, MLR. Sala de aula invertida na educação para profissões de saúde: conceitos essenciais para a prática. Re. Eletr. Farm. V. 14, n. 1, p 39-48, 2017.

5. CAVALCANTE, CM et al. Desafios do cuidado em saúde mental na estratégia saúde da família. RBPS, Fortaleza, 24(2):102-108, abr./jun.,2011.

6. CAREY, $M$ et al Accuracy of general practitioner unassisted detection of depression. Australian \& New Zealand Journal of Psychiatry, vol. 48(6) 571-578. 2014.

7. CHEN, F. et al. A systematic review of the effectiveness of flipped classroonms in medical education. Medical Education, 51:585-597, 2017.

8. CHIAVERINI, D.H. et al. Guia prático de matriciamento em Saúde Mental. Brasília: Ministério da Saúde, Centro de Estudos e Pesquisa em Saúde Coletiva, 2011.

9. CORREIA, VR; BARROS, S; COLVERO, LA. Saúde mental na atenção básica: prática da equipe de saúde da família. Rev Esc Enferm USP, 45(6):1501-6, 2011.

10. ELIZABETH, H.B. et al. Does physician education on depression management improve treatment in primary care? J Gen Intern Med, 16:614-619, 2001.

11. GASK, L. Educating Family Physicians to recognize and manage depression: where are we now? CanJPsychiatry, 58(8):449-455, 2013.

12. GONÇALVES, D.A. et al. Evaluation of a mental health training intervention for multidisciplinary teams in primary care in Brazil: a pre and posttest study. General Hospital Psychiatry, 2013.

13. GRYSCHEK, G; PINTO, AAM. Saúde Mental: como as equips de saúde da família podem integrar esse cuidado na atenção básica. Ciência \& Saúde Coletiva, 20(10):355-326, 2015. 
14. HEITZ, C. et al. Does the concept of the "Flipped Classroom"extend to the emergency medicine clinical clerkship? Western Journal of Emergency Medicine, volume XVI, NO.6, 2015.

15. HEW, K.F.; LO, C.K. Flipped classroom improves student learning in health professions education: a meta-analysis. BMC Medical Education, 18:38, 2018.

16. JESEN, J.L. et al. Improvements from a Flipped Classroom May Simply Be the Fruits of Active Learning. Life Sciences Education, vol. 14 1-12, 2015.

17. LAM, T.P. et al. What do primary care doctors get out of a year-long postgraduate course in community psychological medicine? INT'L J Psychiatry in medicine, vol. 42(2) 133-149, 2011.

18. LAM, T.P.L. et al. Does postgraduate training in community mental health make a difference to primary care physicians attitudes to depression and schizophrenia? Community Mnet Health J, 2015.

19. LEVAV, I. et al. Training latin American primary care psysicians in the WPA module on depression: results of a multicenter trial. Psychol Med, 35(1):35-45, 2005.

20. LIMA, E.F.A. et al. Perfil socioprofissional de trabalhadores de equips de saúde da família. Rev Enferm UERJ, 24(1):e9405, 2016.

21. LIN, E.H. et al. Achieving guidelines for the treatment of depression in primary care: is physician education enough? Medical Care, 35(8):831-421997

22. KAKUMA, R et al. Human resources for mental health care: current situation and strategies for action. Lancet; 378:1654-63, 2010.

23. KIRKPATRICK, D. Evaluation of training. In: Craig RL, Bittel LR, eds. Training and Development Handbook. New York, NY: McGraw-Hill 1967;87-112.

24. KROENKE, K. et al. Anxiety Disorders in primary care: prevalence, impairment, comorbidity, and detection. American College of Physicians, 146:317-315, 2007.

25. KUTCHER, S.P. et al. Evaluating the impact of an educational program on practice patterns of Canadian family physicians interested in depression treatment. J Clin Psychiatry, 4(6), 2002.

26. KUTCHER, S.P. et al. Short term educational intervention improves family physicians knowledge of depression. J Contin Educ Health Prof, vol. 23 239-243, 2003. 
27. MARIN, R. et al. Chile: acceptability of a training program for depression management in primary care. Front. Psychol. 7:853, 2016.

28. MARGULIEX, L. et al. C21U`s Guide to Flipping your Classroom. 2013 Disponível

em: http://c21u.gatech.edu/sites/default/files/Flipped\%20Classroom\%20Guide final.pdf . Acesso em 19 dez 2016.

29. MEDINA, CO; KULLGREN,G; DAHLBLOM, K. A Qualitative study on primary health care professionals's perceptions of mental health, suicidal problems and help-seeking among young people in Nicaragua. BMC Family Practice, 15:129, 2014.

30. MINISTÉRIO DA SAÚDE. Portaria $\mathbf{N}^{\mathbf{0}} \mathbf{3 . 0 8 8}$, de 23 de dezembro de 2011. Brasília, ministério da saúde. 2011. Ciência \& Saúde Coletiva, 20(2):525-536, 2015.

31. MITCHELL, A. et al. Clinical diagnosis of depression in primary care: a metaanalysis. Lancet, 374:609-19, 2009.

32. MUSSE, J.O. et al. Avaliação de competências de agentes comunitários de saúde para coleta de dados epidemiológicos. Ciência \& Saúde Coletiva, 20(2):525-536, 2015.

33. NORTON, J.L. et al. Beliefs and attitudes of French family practitioners toward depression: the impact of training in mental health. Int $\mathrm{J}$ Psychiatry Med, 41(2):107-122, 2011.

34. OLARIU, E. et al. Detection of anxiety disorders in primary care: a meta-analysis of assisted and unassisted diagnoses. Depression and Anxiety 0:1-14, 2015.

35. OLIVEIRA, AGB; CONCIANI, ME; MARCON, SR. A capacitação e a gestão de equips do PSF para a atenção psicossocial: um estudo de caso. Cienc Cuid Saúde, 7(3):376-384, 2008.

36. ORGANIZAÇÃO MUNDIAL DA SAÚDE. Integrating mental health into primary care, A global perspective. OMS, 2008.

37. ORGANIZAÇÃO MUNDIAL DA SAÚDE. Mental Heatlh Atlas. OMS, 2014.

38. PREFEITURA DO MUNICÍPIO DE UBEARABA, disponível em http://www.uberaba.mg.gov.br/portal/acervo/saude/arquivos/unidades_basicas.pdf acessado em 14 fev 2016. 
39. SHARMA, N. et al. How we flipped the medical classroom. Medical Teacher, 37:327-330, 2015.

40. SOUZA, C.S. et al. Estratégias Inovadoras para Métodos de ensino tradicionais Aspectos gerais. Revista Medicina (Ribeirão Preto), 47(3):284-92, 2014.

41. TIEMENS, B.G. et al. Training primary-physicians to recognize, diagnose and manage depression: does it improve patient outcomes? Psychologial Medicine, 29, 833-845, 1999.

42. TITUS, W.D.P. et al. Are effects of depression management training for General Practitioners on patient outcomes mediated by improvements in the process of care? Journal of Affective Disorders, vol. 80 173-179, 2004.

43. THOMPSON, C. et al. Effects of a clinical practice guideline and practice based education on detection and outcome of depression in primary care: Hampshire depression project randomized controlled trial. The Lancet, vol. 355:185-91, 2000.

44. TRIPP, D. Pesquisa-ação: uma introdução metodológica. Educação e pesquisa, v. 31, n. 3,p. 443-466, 2005.

45. TURRINA, C. et al. Immediate and 8 month impact of a medical educational course for general practitioners on knowledge abaut schizophrenia and its treatment: results of a 3 phase study from Brescia, Italy. J Clin Psychiatry, 10:457461, 2008.

46. VALENTINI, W. Et al. Treinamento de Clínicos para diagnóstico e tratamento da depressão. Revista Saúde Pública, 38(4):522-8, 2004.

47. VECCHIA, MD; MARTINS, STF. Concepções dos cuidados em saúde mental por uma equipe de saúda da família, em perspectiva histórico-cultural. Ciência \&Saúde Coletiva, 14(1):183-193,2009.

48. VIANA, M.C.; ANDRADE, L.H. Lifetime Prevalence, Age and Gender Distribution and Age-of-Onset of Psychiatric Disorders in the São Paulo Metropolitan Area, Brazil: Results from the São Paulo Megacity Mental Health Survey. Revista Brasileira de Psiquiatria, 34:249-260, 2012.

49. VOHRINGER, PA et al. Helathcare team training programs aimed at improving depression management in primary care: a systematic review. Journal of Affective Disorders, 200 142-147. 2016. 
50. YOUNG, T.P. et al. The flipped classroom: a modality for mixed asynchronous and synchronous learning in a residency program. West J Emerg Med, vol. 15, No 7, 938-44, 2014.

51. ZAKROYEVA, A. et al. Training Russian family physicians in mental health skills. European Journal of General Practice, 14:1, 19-22, 2009.

52. ZANETTI, T.G. et al. Perfil socioprofissional e formação de profissionais de equipes de saúde da família: um estudo de caso. Cienc cuid Saude, 9(3):448-455, 2010. 
Apêndice 1: Questionário Sociodemográfico

\begin{tabular}{|c|c|c|}
\hline \multicolumn{3}{|c|}{ Dados de Identificação } \\
\hline \multicolumn{3}{|l|}{ Iniciais do participante: } \\
\hline Data de Nascimento: & Idade: & Sexo: 1 Masculino 2 Feminino \\
\hline \multicolumn{3}{|c|}{ Estado Civil: 1 Casado, 2 Amasiado (mora junto), 3 Solteiro, 4 Viúvo, 5 Divorciado, 6 Outros } \\
\hline \multicolumn{3}{|c|}{$\begin{array}{l}\text { Escolaridade: } 1 \text { Fundamental incompleto, } 1 \text { Fundamental completo, } 3 \text { Médio incompleto, } \\
\qquad \text { Médio completo, } 5 \text { Superior incompleto, } 6 \text { Superior completo, } \\
\square \text { Pós Graduação incompleto, } 8 \text { Pós Graduação completo } \\
\text { Número total de anos de estudo: }\end{array}$} \\
\hline \multicolumn{3}{|c|}{ Cor: 1 Branco, 2 Preto, 3 Pardo, 4 Indigena, 5 Asiático, 6 Outros: } \\
\hline \multicolumn{3}{|c|}{ Atualmente trabalha alocado no: 1 PSF, 2 NASF, 3 UBS, 4 Outros: } \\
\hline \multicolumn{3}{|c|}{$\begin{array}{l}\text { Cargo que exerce na prefeitura: } 10 \text { Agente Comunitário de Saúde, } 2 \text { Dentista, } 3 \text { Auxiliar Dentista, } \\
4 \text { Técnico/auxiliar de Enfermagem, } 5 \text { Médico(a), } 6 \text { Enfermeiro(a), } 7 \text { Psicólogo(a), } 8 \text { Fisioterapeuta, } \\
\square \text { Assistente Social, } \square \text { Outros: }\end{array}$} \\
\hline
\end{tabular}

\begin{tabular}{|c|c|}
\hline \multicolumn{2}{|l|}{ Acesso a Internet } \\
\hline Possui computador com acesso a internet em sua casa? & 1 Sim, 2 Não \\
\hline Possui celular ou tablet com acesso a internet? & 1 Sim, 2 Não \\
\hline \multicolumn{2}{|c|}{$\begin{array}{l}\text { Em média, com que frequência você acessa a internet? } 1 \text { Nunca ou menos de uma vez ao mês, } 2 \text { Mais e } \\
\text { uma vez ao mês e menos do que uma vez por semana, } 3 \text { Ao menos uma vez por semana, } 4 \text { Duas a três } \\
\text { vezes por semana, } 5 \text { Três a quatro vezes por semana, } 6 \text { Cinco ou mais vezes por semana. }\end{array}$} \\
\hline Possui conta própria no facebook? & $19 \mathrm{Sim}, 2 \mathrm{Não}$ \\
\hline Acessa o youtube? & 1 Sim, 2 Não \\
\hline Possui conta própria no WhatsApp? & 1 Sim, 2 Não \\
\hline Já realizou algum curso a distância online anteriormente (sobre qualquer assunto)? & 1 Sim, 2 Não \\
\hline
\end{tabular}

\begin{tabular}{|c|c|}
\hline \multicolumn{2}{|l|}{ Psiquiatria/Saúde Mental } \\
\hline Qual o seu interesse em psiquiatria? & 3 Médio; 4 Muito \\
\hline \multicolumn{2}{|c|}{$\begin{array}{l}\text { Você possui alguma pessoa próxima com algum transtorno mental (por ex. depressão, ansiedade, } \\
\text { alcoolismo, uso de drogas, demência, etc) } \\
\text { Sim, } 2 \text { Não }\end{array}$} \\
\hline \multicolumn{2}{|c|}{$\begin{array}{l}\text { Se você respondeu sim à questão anterior, você acha que seu interesse em psiquiatria seja maior por conta } \\
\text { disto? } \\
\text { Sim; } 20 \text { Não }\end{array}$} \\
\hline Já fez algum curso sobre psiquiatria/ saúde mental depois de formado? & 11 Sim; 2 Não \\
\hline \multicolumn{2}{|c|}{ Se você respondeu sim à questão anterior, quantos, quando e quais cursos realizou? } \\
\hline \multicolumn{2}{|c|}{$\begin{array}{l}\text { Você se considera preparado para lidar com as demandas de saúde mental no seu trabalho? } \\
\square \text { Me acho totalmente despreparado, } 2 \text { Me acho pouco preparado, } 3 \text { Me acho bastante preparado, } \\
\square \text { Me acho totalmente preparado }\end{array}$} \\
\hline Quais tópicos você gostaria que fossem abordados neste curso de psiqu & \\
\hline
\end{tabular}


Apêndice 2: Prova de Avaliação de Conhecimentos

\section{Curso de Capacitação em Saúde Mental \\ Questionário de Avaliação de Conhecimentos}

Iniciais do participante:

Data:

Profissão:

Instruções

- Esta avaliação tem por objetivos: avaliar o aprendizado individual de cada participante; avaliar se o curto atingiu seus objetivos de aprendizagem; rever e reforçar conceitos importantes em saúde mental.

- Será feita correção das questões após término da prova.

- Esta avaliação não tem influência sobre o certificado de realização do curso.

- Somente escreva nos espaços destinados à respostas, as quais devem ser objetivas.

- A prova de todos será recolhida após correção. Porém, somente serão utilizados os dados daqueles que assinaram o termo de consentimento livre e esclarecido para participação da pesquisa.

- Tempo de duração: 50 minutos

\section{Questão 1}

Maria das Dores, 43 anos, conta que "não é mais a mesma". Desde que seu filho saiu de casa há 4 meses, tem ficado cada vez pior. Desde há 2 meses "só chora o dia todo", "só quer ficar na cama", "não tem vontade de fazer mais nada", "passa a noite em claro", "a comida não desce" tendo perdido $4 \mathrm{~kg}$, "não tem ânimo para nada", acha que "não serve mais pra nada" já que "não tem mais ninguém que depende" dela.

Maria das Dores já faz seguimento no PSF há 2 anos. Não apresenta comorbidades clínicas, não faz uso de nenhuma medicação ou drogas, seus exames complementares de rotina (incluindo hemograma e TSH) não tem alterações, é sedentária. A equipe do PSF também já tem informações sobre contexto social e familiar, situação laboral e econômica, relacionamentos interpessoais de Maria, histórico de vida e características de personalidade. 
a) Cite dois aspectos da história que ainda precisam ser investigados, pois são fundamentais para se definir o local mais adequado de tratamento e o tempo de tratamento medicamentoso.

b) Cite 2 medidas não medicamentosas que poderiam beneficiar o tratamento de Maria das Dores.

\section{Questão 2}

Mariano busca ajuda no PSF. Conta que sua filha Francisca, 32 anos, parou de ir às consultas psiquiátricas há meses e, há um mês, parou de tomar as medicações. Desde há duas semanas Francisca é vista falando sozinha, diz ouvir vozes, acredita que os vizinhos estão "armando para cima dela", as vezes não come por acreditar que a comida esta envenenada.

Além disso fica agitada e irritada na maior parte do dia e não deixa ninguém dormir pela noite. Tem ficado cada vez mais agressiva, tanto contra seus familiares como com os vizinhos. Já realizou diversas agressões físicas contra familiares e terceiros, quebrou objetos da casa, e até mesmo "deu pauladas" em uma vizinha grávida. Mariano conta que não tem coragem de voltar para casa pois Francisca está o ameaçando de morte.

a) Francisca apresenta comportamento que revela presença de sintomas psicóticos, como ouvir vozes (alucinações auditivas) e acreditar que estão "armando para cima dela" e envenenando sua comida (delírios). Cite 5 causas ou condições comuns que podem provocar sintomas psicóticos 
b) Qual a principal conduta que a equipe do PSF deve tomar diante de tal situação?

\section{Questão 3}

Para cada descrição abaixo, cite o diagnóstico mais provável.

a) Repetidos períodos ou "crises" em que o paciente sente palpitações, sudorese, tremor, dispneia (falta de ar), sensação de sufocamento, dor no peito, náuseas, tonturas, formigamentos, sensação de que vai morrer ou de estar enlouquecendo. Tais episódios ocorrem sem desencadeante, atingem pico em menos de 10 minutos, normalmente duram até 30 minutos. O paciente fica muito preocupado se terá novas crises.

Qual o diagnóstico mais provável?

b) Medo ou ansiedade excessiva de situações em que o paciente sente que pode estar sendo julgado ou avaliado negativamente pelos outros, como falar em público, ir a eventos sociais, falar com desconhecidos, comer em público, dentre outros. O paciente evita passar por tais situações ou as suporta às custas de intensa ansiedade.

Qual o diagnóstico mais provável?

c) Medo excessivo de objetos, animais ou situações específicas, como: altura, locais fechados, insetos, sangue, dentre outros. O indivíduo evita entrar em contato com o que provoca tal medo e tem reações de intensa ansiedade quando entra em contato.

Qual o diagnóstico mais provável? 
d) Ansiedade e preocupações persistentes e excessivas acerca de vários domínios diferentes. O paciente tem dificuldade de relaxar e controlar tais preocupações, pode sentir insônia, irritabilidade, tensão muscular, sensação de estar com os nervos a flor da pele, inquietação e fatigabilidade aumentada.

Qual o diagnóstico mais provável?

\section{Questão 4}

Dona Elmira, 68 anos, faz uso de 2 comprimidos de clonazepam $2 \mathrm{mg} / \mathrm{cp}$. há mais de 10 anos. Diz que "não pode ficar sem o remédio" senão "não dorme nada". Apesar de reconhecer que está "viciada" no clonazepam, dona Elmira não vê porque tentar parar de usar a medicação já que o ela "nunca fez mal".

a) Para conscientizar dona Elmira sobre a importância de realizar "desmame" do clonazepam sob supervisão médica, cite 2 possíveis consequências danosas de manter o uso crônico do remédio.

1

2

b) Descreva de qual classe é cada medicação abaixo:

Ex. Venlafaxina: antidepressivo, inibidor da recaptura de serotonina e noradrenalina.

\section{Clonazepam:}

2 Fluoxetina:

3 Haloperidol: 


\section{Questão 5}

Marilda se queixa que "não dorme bem pela noite", "demora muito pra pegar no sono" e "tem sono leve, acordando com qualquer coisa". Investigando seu cotidiano e fatores ligados à higiene do sono, Marilda conta que pela semana se deita às 23:00 e levanta às 07:00, mas nos fins de semana se deita às 01:00 e dorme "quase até o almoço".

Para "ajudar a pegar no sono", toma um banho bem quente antes de dormir, bebe uma taça de vinho e fica deitada mexendo no facebook do celular "até pegar no sono", pois normalmente deita sem sentir sono.

Quando acorda pela noite sem sono, vai ao banheiro e depois fica "rolando na cama" até voltar a sentir sono.

Não costuma fazer uso de café ou energéticos. Frequenta a academia pela manhã, sendo que logo depois vai para o trabalho. Tem costume de ler e usar o notebook na cama e tirar "cochilos" de até 2 horas pela tarde para "repor" o que "não dormiu de noite".

Cite 4 hábitos de Marilda que podem prejudicar seu sono.

1

2

3

4 
Apêndice 3: Questionário de Auto Avaliação

\section{Questionário de Auto Avaliação, Satisfação e Feedback}

Iniciais do participante: Data: Profissão:

Atribua um valor de 1 a 5 conforme a escala abaixo para expressar domínio que você acredita ter em cada um dos tópicos listados a seguir, considerando você ANTES e DEPOIS de ter participado deste curso:

ESCALA:

1 Me sinto DESPREPARADO (conhecimento e habilidade) para lidar com este tema. $2 \mathrm{Me}$ sinto com POUCO conhecimento, habilidade e preparo para lidar com este tema. $3 \mathrm{Me}$ sinto com ALGUM conhecimento, habilidade e preparo para lidar com este tema. $4 \mathrm{Me}$ sinto com conhecimento, habilidade e preparo SUFICIENTES para lidar com este tema. $5 \mathrm{Me}$ sinto MUITO COMPETENTE para lidar com este tema - poderia ensinar outras pessoas.

\begin{tabular}{|l|l|l|}
\hline Tópicos em psiquiatria e saúde mental & Antes & Depois \\
\hline 1. Rede de atenção psicossocial & & \\
\hline 2. Psicofarmacologia (medicamentos na psiquiatria) & & \\
\hline 3. Manejo da depressão & & \\
\hline 4. Manejo de pessoas com risco ou tentativa de suicídio & & \\
\hline 5. Manejo dos transtornos de ansiedade & & \\
\hline 6. Reconhecimento de Demência & & \\
\hline 7. Insônia & & \\
\hline 8. Manejo do paciente em agitação psicomotora & & \\
\hline $\begin{array}{l}\text { 9. O meu preparo para lidar com as demandas em saúde mental em } \\
\text { geral }\end{array}$ & & \\
\hline
\end{tabular}

Por favor comente sobre algo significativo que você aprendeu ou entendeu melhor durante este curso.

O que você aprendeu no curso que poderá ser útil na sua prática profissional? 
Apêndice 4: Questionário de Satisfação e Feedback

Agora, gostariamos de saber a SUA IMPRESSÃO sobre a experiência que VOCÊ teve neste curso de psiquiatria/saúde mental.

Por favor, avalie cada um dos aspectos mencionados, usando a escala abaixo apresentada (marque com um " $\mathrm{X}$ ")

1 Muito Ruim; 2 Ruim; 3 Regular; 4 Bom; 5 Muito bom

\begin{tabular}{|l|l|l|l|l|l|}
\hline Aspecto & 1 & 2 & 3 & 4 & 5 \\
\hline Pertinência do conteúdo (tópicos escolhidos) & & & & & \\
\hline Estratégias de ensino & & & & & \\
\hline Cumprimento dos objetivos propostos & & & & & \\
\hline Desempenho dos professores & & & & & \\
\hline Sua participação & & & & & \\
\hline Participação de sua equipe de PSF & & & & & \\
\hline Participação da sala de aula como um todo & & & & & \\
\hline Materiais suplementares oferecidos (textos, escalas, sțs) & & & & & \\
\hline Vídeo-Aulas (somente para turma com ensino a distância) & & & & & \\
\hline
\end{tabular}

1 Destaque os aspectos mais positivos do curso:

2 Destaque os aspectos que poderiam ser modificados ou aprimorados:

3 Somente para alunos do curso misto (presencial e a distância). O que você achou de ter parte do seu curso com aulas não presenciais?

4 Somente para alunos do curso misto (presencial e a dist6ancia). O que você achou da qualidade geral das vídeo aulas $\mathrm{e}$ textos suplementares? 
Apêndice 5: Termo de Consentimento Livre e Esclarecido

\author{
UNIVERSIDADE DE SÃO PAULO \\ FACULDADE DE MEDICINA DE RIBEIRÃO PRETO - USP
}

Projeto de Pesquisa: Avaliação da Educação Semipresencial em Saúde Mental para

Capacitação de Equipes de Saúde da Família.

\title{
TERMO DE CONSENTIMENTO LIVRE E ESCLARECIDO
}

Meu nome é Tomás Rotelli de Oliveira Ferreira, sou médico e aluno de pós- graduação sob a coordenação e orientação do professor Valdes Roberto Bollela, médico e professor da Faculdade de Medicina de Ribeirão Preto da Universidade de São Paulo.

Gostaríamos de convidá-lo a participar de nossa pesquisa intitulada "Avaliação da Educação Semipresencial em Saúde Mental para Capacitação de Equipes de Saúde da Família.” O objetivo será de avaliar as potencialidades e limitações de duas abordagens diferentes de capacitação em saúde mental (curso presencial e semi-presencial). Você está sendo convidado a participar da modalidade presencial, que ocorrerá uma vez por semana durante 6 semanas, com tempo estimado de 3 horas em cada encontro, a serem realizados na sala de aula da Secretaria de Saúde do Município de Uberaba.

Além de você assistir nossas aulas, você deverá também responder um questionário escrito sócio demográfico contendo: idade, sexo, estado civil, escolaridade, cor, local de trabalho, profissão, se possui computador com acesso a internet, frequência que acessa internet, se possui conta no facebook, se acessa o youtube, se possui conta no WhatsApp, se já realizou algum curso a distância, qual o seu interesse na psiquiatria, se possui alguma pessoa próxima com algum transtorno mental, se já fez algum curso em psiquiatria e se considera preparado para lidar com as demandas de saúde mental.

A sua participação, desistência ou negação em participar deste projeto de pesquisa não lhe terá riscos em relação a sua estabilidade profissional ou qualquer prejuízo em participar dos cursos ofertados. 
Não será permitida a divulgação ou reprodução do material científico sem prévia autorização dos pesquisadores.

Todas as informações que nos disser serão mantidas sob nossa guarda e responsabilidade e também serão utilizadas somente para essa pesquisa. Assim, será garantido sigilo assegurando a sua privacidade quanto aos dados confidenciais envolvidos na pesquisa e a garantia que será preservado o anonimato, isto é seu nome não constará nos instrumentos.

Esse estudo trará benefícios diretos a você, por ofertar capacitação em saúde mental. O único risco que acreditamos que pode te oferecer é lhe causar constrangimento e desconforto relacionados aos itens que terei que pergunta-lo do instrumento.

A sua participação na pesquisa é de caráter voluntário, ou seja, você pode decidir se quer ou não participar do estudo. Você pode também decidir parar de participar a qualquer momento, basta informar ao pesquisador. A decisão de não participar da pesquisa não afeta a sua participação como estudante do curso. Você não terá gastos e não receberá dinheiro para participar da pesquisa. Você tem direito à indenização, conforme as leis vigentes no país, caso ocorra dano decorrente da participação na pesquisa, por parte do pesquisador e das instituições envolvidas nas diferentes fases da pesquisa. Se você concordar em participar, por favor, assine duas cópias desse documento, que se chama Termo de Consentimento Livre e Esclarecido, após ter a oportunidade de tirar suas dúvidas comigo. Você receberá uma das cópias originais desse termo assinada por e poderá me solicitar para retirar dúvidas ou cancelar sua participação a qualquer momento.

Esta pesquisa foi analisada e aprovada pelo Comitê de Ética em Pesquisa com Seres Humanos (CEP) da Faculdade de Medicina de Ribeirão Preto/USP, pois respeita as questões éticas necessárias para a sua realização. O CEP também tem a finalidade de proteger as pessoas que participam da pesquisa e preservar seus direitos. Assim, se for necessário, entre em contato com este CEP pelo telefone 16-3602-2228, ou pelo endereço: Avenida dos Bandeirantes, 3900- Campus Universitário, Ribeirão Preto, SP, CEP: 14040-902. Horário de atendimento: de segunda à sexta-feira por dias úteis no horário das 8:00 às 17:00h.

Agradecemos a sua colaboração. Uberaba, 07 de abril de 2016

\section{Pesquisadoras responsáveis:}

Tomás Rotelli de Oliveira Ferreira. E-mail: tomasferreira@me.com

Prof. Valdes Roberto Bollela. E-mail: bollela@gmail.com 
Após ter conhecimento sobre como poderei colaborar com esta pesquisa, concordo com minha participação, que decidi por livre e espontânea vontade.

$\mathrm{Eu}$, , RG:

aceito fazer parte desta pesquisa, contribuindo com a participação em um encontro para responder aos instrumentos e entrevista. Durante minha participação, sei que vou falar sobre meus dados sociodemográficos e meu ambiente familiar. Estou ciente de que quando eu não quiser mais participar, eu posso desistir sem qualquer conseqüência para mim. Sei, também, que ao final desta pesquisa, o meu nome será mantido em segredo. Recebi uma via original deste documento, assinada pela pesquisadora responsável e sua orientadora, e tive a oportunidade de discuti-lo com, pelo menos, uma delas.

Nome do participante

Assinatura do participante

Data:

Tomás Rotelli de Oliveira Ferreira

Nome do pesquisador

Assinatura do pesquisador

Data:

Prof. Valdes Roberto Bollela

Pesquisador Responsável/Orientador

Uma via deste termo de consentimento deverá ser fornecida ao participante. 